Cómo citar este trabajo: Martínez Sánchez, J., \& Martínez-Carrasco Martínez, L. (2019). Procesos socioterritoriales de un paisaje rural en riesgo de "musealización": el ENP la Muela, Cabo Tiñoso y Roldán (Cartagena, España). Boletín de la Asociación de Geógrafos Españoles, 80, 2611, 1-37. http://dx.doi.org/10.21138/bage.2611

\title{
Procesos socioterritoriales de un paisaje rural en riesgo de "musealización": el ENP la Muela, Cabo Tiñoso y Roldán (Cartagena, España)
}

\author{
Musealised landscapes in rural areas. \\ The case on Cabo Tiñoso Natural Park (Cartagena, Spain)
}

\author{
José Martínez Sánchez \\ j.martinezsanchez@um.es \\ Departamento de Didáctica de las Ciencias Experimentales \\ Universidad de Murcia (España)

\section{Laura Martínez-Carrasco Martínez} \\ Imartinez@umh.es \\ Departamento de Economía Agroambiental, \\ Ing. Cartográfica y Expresión Gráfica en la Ingeniería \\ Universidad Miguel Hernández de Elche (España)
}

\section{Resumen}

El paisaje agroforestal del ENP "La Muela, Cabo Tiñoso y Roldán" (Cartagena-España) aparece como resultado de una histórica adaptación a las culturas locales. Mediante el análisis cualitativo de entrevistas a actores sociales, expertos locales y gestores del territorio, apoyadas en el estudio documental, este trabajo persigue conocer la interacción de los procesos socioterritoriales con el riesgo de "musealización" del paisaje rural. Nuevos pobladores y visitantes, muchos de ellos extranjeros europeos, ejercen funciones inéditas en el territorio, al tiempo que retrocede la importancia de la población local en la gestión activa del paisaje. El gran incremento en la demanda de viviendas - vacacionales o dormitorio- derivada de la proximidad a Cartagena y el atractivo de 
sus paisajes, y los cambios en su distribución y tipología arquitectónica, contrastan con el ajuste tradicional de la población a las posibilidades agrarias. Mientras crece la intervención en el paisaje del ecoturismo y, sobre todo, del deporte en la naturaleza, retroceden las tradicionales actividades agropecuarias debido al difícil reemplazo generacional, la sequía y la escasa rentabilidad. Las políticas de gestión y planificación del ENP no han desarrollado los instrumentos participados para invertir el proceso de "musealización" de un paisaje difícilmente conservable sin la actividad antrópica.

Palabras clave: paisaje; rural; naturbanización; rururbarno; Espacio Natural Protegido.

\begin{abstract}
The agroforestry landscape of the "La Muela, Cabo Tiñoso and Roldán" Natural Park (CartagenaSpain), is been modelled as a result of the historical adaptation to local cultures. Based on a qualitative analysis of interviews with local agents, experts and territorial managers, this article makes a case for the relevance of the socioterritorial activity related to the risk of 'musealization' of the rural landscape. The new visitors and settlers, many of them foreigners, develop new functions in the territory, while the active management of the local population as is getting less important. The sharp increase in the demand for sleepy and holiday's residencies, due to the proximity to the city of Cartagena and the beauty of its landscapes, contrasts with the traditional distribution of population adjusted to the topography and the agrarian possibilities. The rise of ecotourism and, above all, sports in nature, takes part in a different way respect to traditional agricultural activities, according to the lack of agricultural profitability and the difficulties of generational replacement. The management and planning policies of the Natural Park have not developed participatory instruments to reverse the process of "musealization", ignoring that maintaining the socioeconomy activity is essential for its conservation.
\end{abstract}

Key words: landscape; countryside; naturbanization; rururban; Protected Natural Area.

\title{
1 Introducción
}

El Espacio Natural Protegido (ENP) La Muela, Cabo Tiñoso y Roldán se localiza ocupando el centro meridional de la Región de Murcia (Sureste de España) y el Oeste del Término Municipal de Cartagena, en el que se incluye casi la totalidad de su territorio. Esta área protegida de 11361,04 ha forma parte de las Sierras Occidentales de Cartagena, que acaba hacia el Sur en la línea costera del Mar Mediterráneo. La carretera N332 Cartagena-Mazarrón supone el límite del ENP en su zona Norte, siendo la Rambla de Valdelentisco su límite Oeste. El ámbito Este envuelve el entorno de la ciudad de Cartagena en la zona de Tentegorra, Los Flores y Canteras, principalmente. El paisaje rural del ENP se ubica en un territorio que alberga diversas figuras de 
protección europeas (Lugar de Interés Comunitario LIC y Zona de Especial Protección para las Aves ZEPA) y regionales (ENP y Área de Protección de la Fauna Silvestre APFS), que varían en su extensión y límites territoriales, siendo la figura regional de ENP la que recoge en su ámbito al resto de figuras legales (Figura 1).

Figura 1. Delimitación de las distintas figuras de protección y dominio público
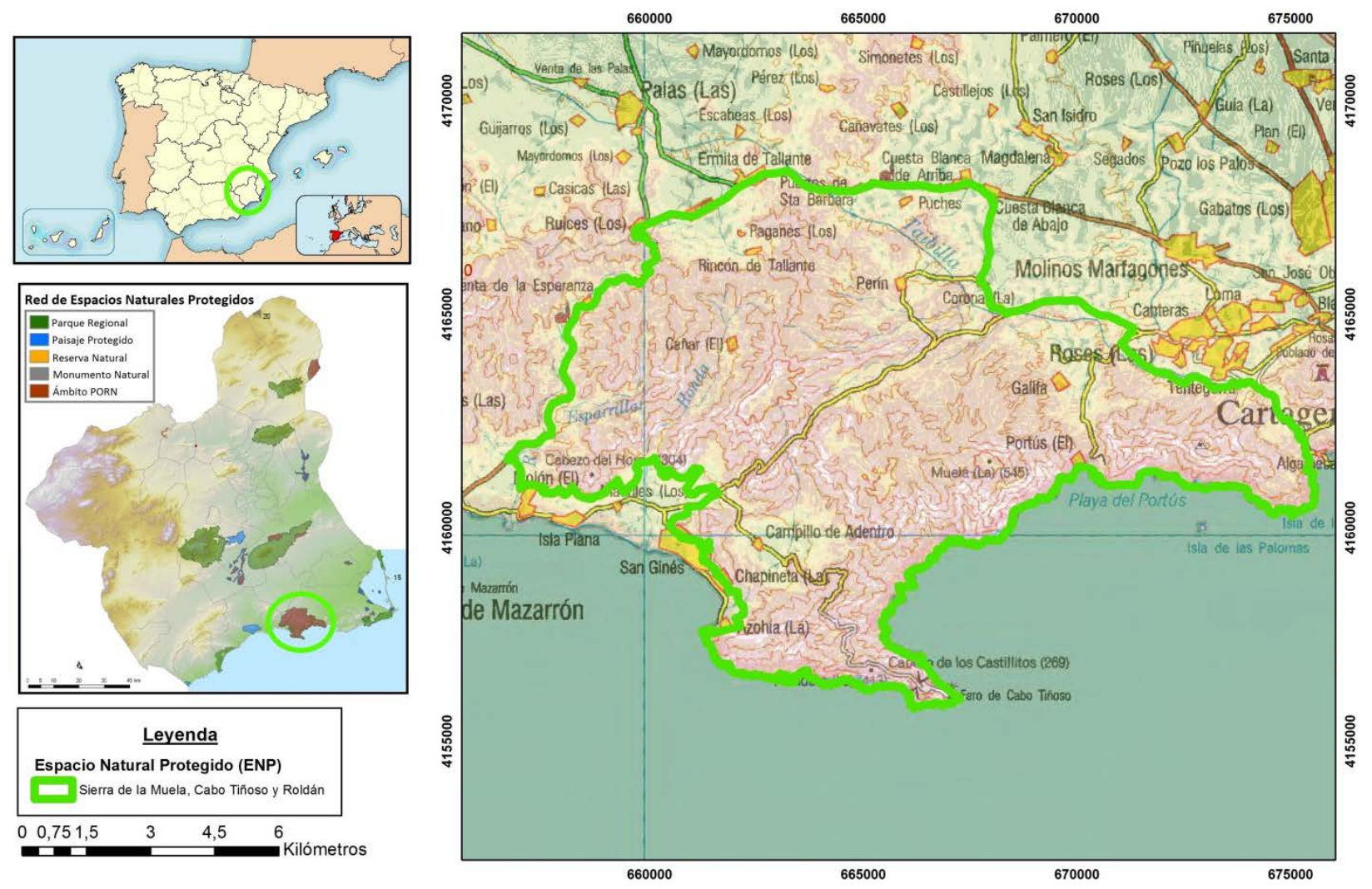

Fuente: elaboración propia a partir de bases cartográficas

del Instituto Geográfico Nacional (IGN) y CARTOMUR

Este Espacio Natural lleva recibiendo durante siglos la acción de la actividad cultural local, que ha permitido obtener el particular paisaje rural característico de la zona (Figura 2). Los recientes y profundos cambios que han sufrido las sociedades locales "modificadoras" del paisaje, están generando nuevas dinámicas socioculturales que afectan a la tradicional convivencia entre los elementos naturales y humanos del paisaje cultural del ENP.

La conceptualización del paisaje rural lleva asociada a la idea de paisaje el resultado de la actuación humana local (de un grupo cultural) sobre el medio natural (Mata Olmo, 2008). El paisaje puede ser considerado una construcción, ya no en su carácter físico, sino como una producción cultural, social e incluso política, cuyo desarrollo se demuestra a lo largo de su evolución histórica. De esta forma, los paisajes evolucionan continuamente de una forma más o menos caótica, reflejando las 
necesidades sociales y económicas de las sociedades de un lugar y momento concreto (Antrop, 2006).

Figura 2. Recopilación de imágenes de distintos paisajes del ENP: vista del mosaico forestal, de cultivos de secano y de viviendas, desde el Monte Roldan (superior izqda.), relieve calcáreo de Peñas Blancas (629 m.s.n.m.) desde la parte alta de La Rambla del Cañar (superior dcha.), acantilados de la Sierra de La Muela y Cabo Tiñoso desde el Cabezo Roldán (inferior izqda.) y masas de pino carrasco de La Muela (inferior dcha.)
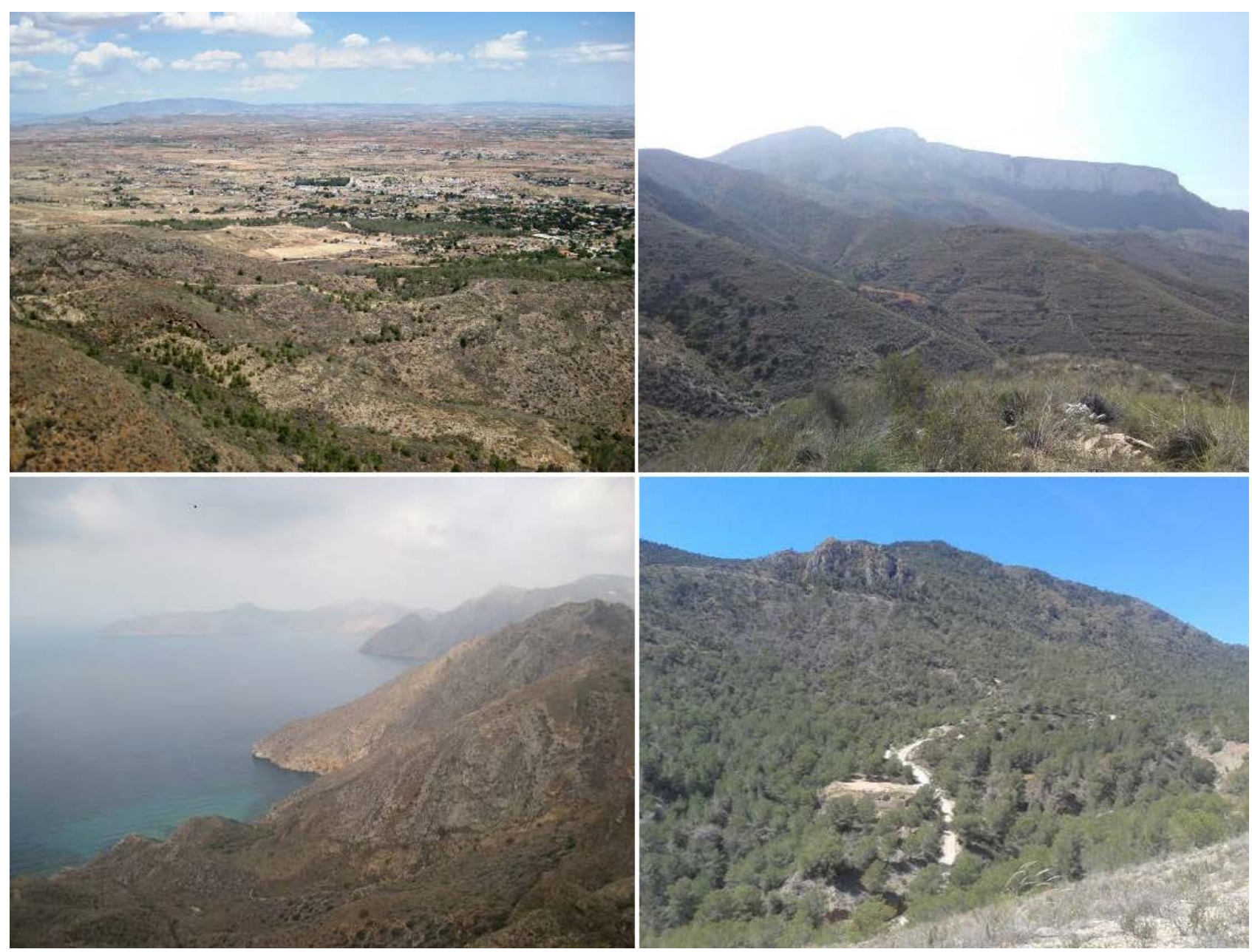

Fuente: elaboración propia

En este proceso constructivo, las sociedades locales aparecen como elemento esencial del carácter creador/modificador de los paisajes. Los paisajes culturales, y por ende los paisajes rurales, no escapan de estos procesos más o menos continuos de la intervención del territorio por el ser humano que genera paisaje (Silva Pérez, 2009; García Ruiz et al., 2018). En este sentido, el paisaje cultural expresa una identidad única y particular de un territorio: al tiempo que se genera una realidad material singular, poseedora de valores inmateriales; se produce una interacción continua y dinámica de procesos naturales y de actividades humanas de especificidad irrepetible (Antrop, 2005). Por su parte, el paisaje forma parte del territorio, entendido éste como un área más 
amplia de características, estructura y composición similares; con un carácter "total", distintivo e identitario. De este modo, los paisajes representan una fracción de las significaciones inmersas en un territorio, ya sean las relaciones que son aportadas sensorialmente al perceptor del paisaje o las inmersas dentro de la complejidad de procesos de los elementos del paisaje (Antrop, 2006).

Al mismo tiempo, para que un territorio o una parte de él genere paisaje debe ser percibido por el ser humano, enlazando a la concepción teórica del paisaje la necesidad de la interpretación del territorio por el ser humano (Serrano Giné, 2007). Por ello, acaba generándose una relación de pertenencia entre el paisaje y sus habitantes, que alberga funciones de construcción y/o fortalecimiento de identidades territoriales a distinta escala, siendo a veces asumidos como propios y reivindicados como localmente identificativos (Roca et al., 2007); de gran importancia por su carácter excepcional dentro de las dinámicas sociales contemporáneas a escala global.

La trasformación de la naturaleza por la acción del hombre que configura los paisajes culturales acaba siendo resultado no tanto del individuo como de un colectivo, y no tanto de un momento concreto como del paso continuado del tiempo (Elías, 2008). Esta íntima relación entre las características de las sociedades y el paisaje ha funcionado tradicionalmente como una interacción equilibrada entre los recursos naturales y las prácticas culturales (Mata Olmo, 2004), reflejándose de manera paradigmática en los paisajes culturales, y de manera más específica, en los paisajes rurales y agrarios (Antrop, 2006). En los paisajes rurales, el cambio en los modelos de producción agraria de las últimas décadas se ha visto altamente influenciado por la reestructuración que ha sufrido el sector en Europa (Mander et al., 1998), en una tendencia polarizada entre la intensificación agrícola y la transformación urbana, más incidentes en áreas periurbanas y costeras, y el abandono de tierras en zonas rurales, normalmente remotas (Antrop, 2006; Roca, 2009).

De este modo, el paisaje cultural, rural y agrario - cada uno en su escala y condición- nos muestra información particular sobre las interacciones que se expresan y que han ido actuando en ese territorio (usos de suelo, organización territorial, distribución parcelaria, estructura socioeconómica, infraestructuras $\square$ ), mostrando los aspectos técnicos, económicos y sociales que han intervenido e intervienen sobre los recursos naturales del paisaje (Santos \& Ganges, 2003). En cualquier caso, los paisajes culturales no se reducen al "asiento material" natural sobre el que los grupos humanos manifiestan su legado cultural, sino que son además, fuente de inspiración y/o subsistencia para las poblaciones locales (Pedroli et al., 2007). En este sentido, es amplia la multifuncionalidad de estos paisajes, tanto de manera directa y normalmente retribuida (producción de alimentos y materias primas); como generando beneficios sociales más ligados a la conservación que al lucro (GómezLimón García et al., 2007).

La aparición de nuevas actividades económicas y/o nuevos pobladores rurales se ha traducido en nuevas oportunidades para revitalizar territorios en riesgo de abandono de sus paisajes (Paquettea 
et al., 2003; Hernández Hernández, 2009). Asimismo, la mayor concienciación ambiental, ha puesto en valor los recursos intangibles del paisaje como recurso de calidad de vida (Silva Pérez, 2009), y ha propiciado el crecimiento en la demanda antrópica de los múltiples servicios aportados por los paisajes culturales (Gómez-Limón García et al., 2014; 2016).

Con la llegada de nuevos pobladores y visitantes y los consecuentes cambios socioeconómicos, entre los que destaca el abandono de muchas prácticas tradicionales, el paisaje puede entrar en riesgo de "musealización". Esta "aculturación" o "deconstrucción" del paisaje, en términos de abandono de las practicas mantenedoras del paisaje (García Ruiz et al., 2018) puede por tanto convertir el territorio en una "isla-museo" al aire libre (Reynard et al., 2018). La transformación de un paisaje a "museo territorio" debido a la importancia de sus prácticas culturales (Padró Werner, 2002; Cobos Rodríguez et al., 2014), puede suponer paradójicamente la pérdida de la identidad local y el mantenimiento de valores paisajísticos ajenos a los locales, pero de mayor atractivo para las sociedades actuales, sobre todo las foráneas al territorio (Bowen et al., 2011; Wheeler, 2014); obviando el carácter de continua evolución del paisaje (Moltó Mantero et al., 2016) y la enorme dificultad de preservar o restaurar los paisajes culturales (Moreira et al., 2006).

\section{Objetivos}

El objetivo general de la investigación es analizar el riesgo de "musealización" del paisaje rural del ENP a partir de la interpretación de los procesos fundamentales que actúan en sus tres componentes: (1) territorio y arquitectura de las viviendas, (2) actividad socioeconómica y (3) relaciones socioculturales y administrativas (Figura 3).

Para alcanzar este objetivo general se plantean los siguientes objetivos específicos:

- Analizar la influencia del clima y la topografía en la distribución inicial de la población en el territorio;

- Conocer los factores incidentes en el posterior crecimiento de población y viviendas;

- Analizar la influencia del cercano medio urbano en el crecimiento de la población y viviendas;

- Describir las nuevas funciones y formas de la arquitectura local;

- Deducir las transformaciones de la actividad socioeconómica del paisaje del ENP, fundamentalmente agricultura, ganadería y caza;

- Caracterizar la creciente actividad ecoturística y deportiva de la zona;

- Descubrir las funciones de los tradicionales pobladores en el mantenimiento del paisaje y el papel que juegan los nuevos habitantes;

- Entender la variedad de identidades territoriales y relaciones sociales que intervienen en la sociedad rural del ENP. 
Figura 3. Esquema de los principales procesos incidentes en los componentes del paisaje del ENP
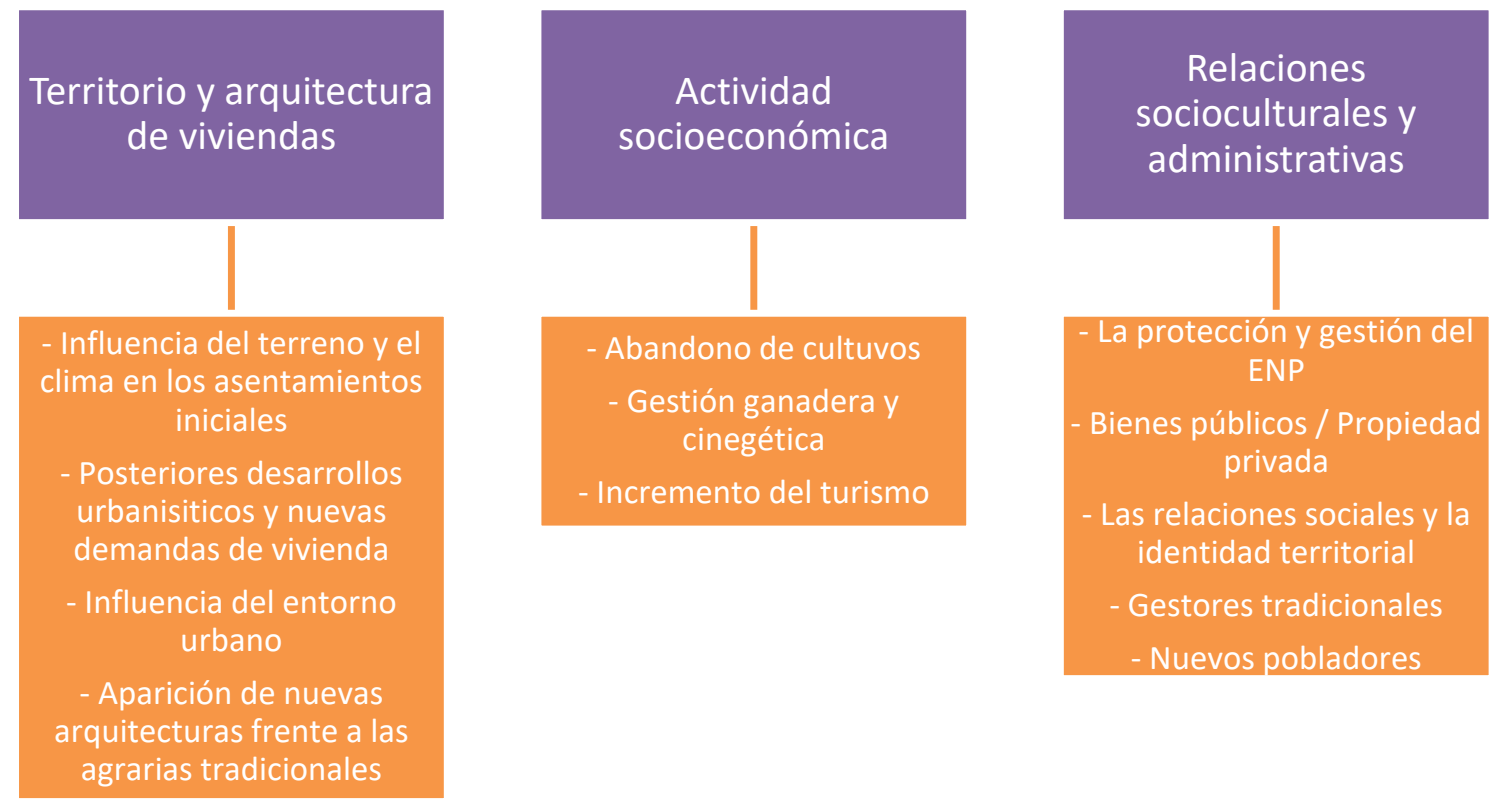

Fuente: elaboración propia

\section{Material y métodos}

La aproximación metodológica utilizada se ha desarrollado en dos etapas: un primer trabajo de revisión bibliográfica, análisis básico de datos cuantitativos sociopoblacionales y contacto previo con el territorio; y una segunda etapa de aplicación de técnicas de investigación cualitativa, a través de la realización de entrevistas que permiten la recogida de información primaria. Se trata de una construcción activa de información en proximidad al protagonista de los hechos y en apoyo al conocimiento existente, basado en un plan de investigación no rígido, de continua redefinición durante el desarrollo del estudio. La recogida de información previa se realizó durante el periodo comprendido entre los años 2013-2016, en los que se trabaja activamente en la realización de diversos estudios técnicos de gestión del ENP para la Administración Ambiental competente.

Las entrevistas se realizaron de manera presencial e individual en el propio territorio del ENP y en las dependencias de la Comunidad Autónoma de la Región de Murcia durante los meses de julioagosto de 2016 y 2017, con una duración variable de 20-70 minutos. Los destinatarios fueron actores locales del entorno rural del ENP (8 entrevistas) y expertos, incluyendo casi todos los técnicos de la administración pública y agentes medioambientales del ENP en los últimos 20 años (7 entrevistas). En las entrevistas se tratan los distintos procesos del paisaje, insistiendo en cada entrevista con los asuntos más relacionados con el entrevistado. Se trata de entrevistas semiestructuradas en las que se sigue un guion previamente definido, pero en las que se favorece la ocurrencia espontánea de temas que puedan ser de interés para la investigación. 
Posteriormente, la información revelada por los entrevistados es analizada, comparada y confirmada/descartada con las manifestaciones de otros entrevistados y la información documental y cuantitativa, con objeto de dar fiabilidad a los resultados expuestos.

\section{Resultados y Discusión}

\subsection{Procesos territoriales y arquitectónicos en el paisaje agroforestal}

a) Influencia del terreno y el clima en los asentamientos iniciales de la población

La difícil topografía que define la acusada cadena montañosa costera de la Sierra de la Muela y el Monte Roldán ha obligado a establecer las redes de comunicación y los asentamientos poblacionales en las zonas más aptas de manera natural. De ahí que los cauces de ramblas, pequeños valles y llanos intermedios han sido históricamente las áreas más utilizadas para estos propósitos (Figura 4). La coevolución de los paisajes y las infraestructuras humanas se relacionan asimismo con la persistencia a largo plazo de la morfología social en el territorio; como ya ha sido descrito en otros ambientes mediterráneos (Tello Aragay, 1999).

Figura 4. Vista de viviendas y núcleos rurales y viviendas diseminadas expandidas en el territorio (izqda.) y núcleo rural costero de El Portús (dcha.)
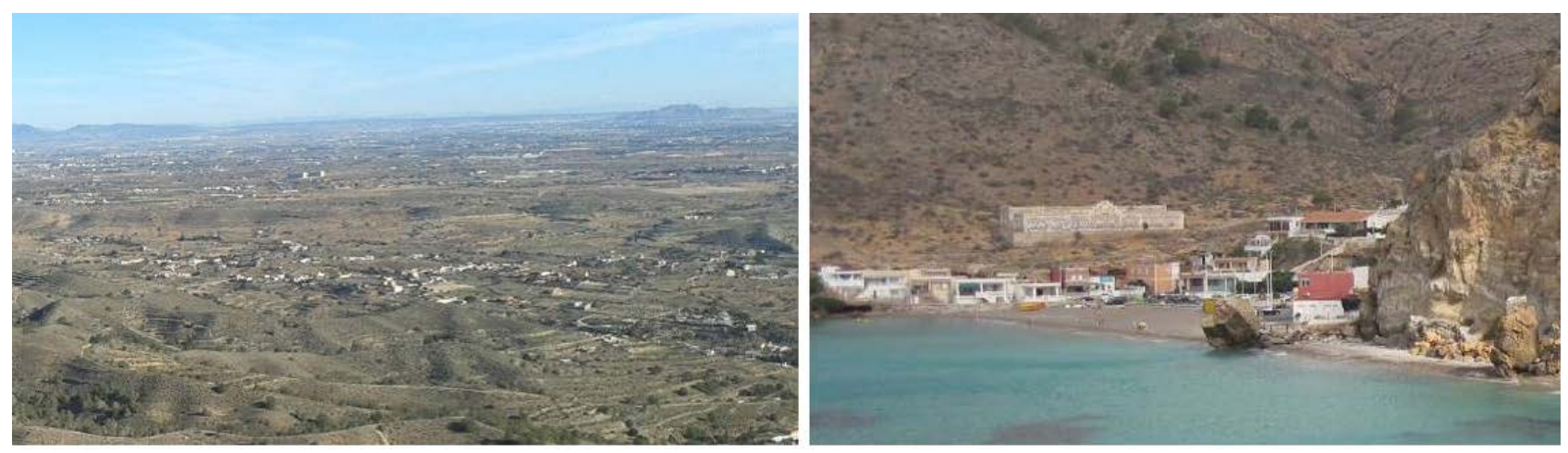

Fuente: elaboración propia

Por otro lado, las condiciones climáticas áridas determinan la actividad rural, dado que la utilización de pozos, norias y otros recursos de extracción de aguas del freático ha definido la ubicación de las poblaciones en las proximidades de ramblas, como se ha identificado en algunas zonas del ENP como Galifa (Berrocal Caparrós, 2007). La falta en la disponibilidad de agua condicionó en origen el mayor crecimiento de los asentamientos poblacionales, que tuvieron que adaptarse a una explotación de cultivos a través del secano. De la mano del abandono de cultivos, se produce un abandono de viviendas y construcciones agrícolas auxiliares que pone en peligro la conservación del patrimonio arquitectónico y cultural del paisaje, como ocurre en la Rambla del Cañar (García Moreno et al., 2007). 
b) Los posteriores desarrollos urbanísticos y las nuevas demandas de viviendas

Desde el asentamiento poblacional de los recolonizadores castellanos, aragoneses y/o navarros a partir del s. XVIII-XIX, la disponibilidad de vivienda había ido siendo satisfecha siguiendo las demandas de crecimiento normal de la población, en equilibrio con las posibilidades agrarias que ofrecía el territorio.

Fue en los años 60-70 cuando comenzó el crecimiento urbanizador en todo el litoral cartagenero. Si bien este proceso no fue para nada tan intenso en el ENP como en otros lugares de la comarca de Cartagena (Rodríguez Alonso et al., 2013), también fue notable sobre todo en las zonas costeras de El Portús o La Azohía. Aunque finalmente el ENP "escapó" del proceso "sobreurbanizador", la zona entre Cabo Tiñoso y La Algameca aparecía calificada como "desarrollo turístico-recreativo" en el Plan General de Ordenación Urbana (PGOU) de Cartagena de 1961, reservando también el uso militar en Cabo Tiñoso y La Algameca (CESIS, 1970).

Paradójicamente, en los pueblos más interiores del ENP finalmente aconteció cierto abandono de viviendas relacionado con el proceso de emigración campo-ciudad que afectó al medio rural español, si bien aquí fue bastante reducido. En cualquier caso, el abandono de viviendas, cuando existió, parece haber afectado en mayor medida a las viviendas aisladas, sobre todo las localizadas en los lugares más difícilmente accesibles; tal y como pareció ocurrir de manera generalizada en amplias zonas de la Región de Murcia (Gil Meseguer, 2006). Además, en muchos casos la vivienda se mantuvo como segunda residencia debido a la proximidad de grandes zonas urbanas.

En las últimas dos-tres décadas, la demanda de viviendas en el ENP empezó a crecer intensamente, partiendo en los años 90 de un contexto particularmente activo en relación a las migraciones internas en la Región de Murcia y en la propia comarca de Cartagena, con la propia ciudad de Cartagena como foco de pérdida de población (Celdrán Iniesta, 2001). En efecto, Ortín García et al. (2013) señalaban la atracción de población que empezaron a experimentar en los años 90 las zonas rurales del entorno de Cartagena y concretamente las del ENP, señalando las Diputaciones de Perín y Los Puertos de Santa Bárbara (ambas parcialmente en el ámbito del ENP) como las que más población ganaban.

Según se desprende de las entrevistas llevadas a cabo entre los actores del territorio, en la llegada de nuevos habitantes a los pueblos del ENP, que podría haber facilitado posteriormente el actual riesgo de "musealización", estuvieron implicados cinco factores principales:

1. Pretensión de vida bajo las condiciones de tranquilidad y calidad paisajística que ofrece el entorno rural del ENP, pero en cercanía a los servicios socioculturales y al trabajo que oferta al entorno urbano de Cartagena. 
2. Deseo de una segunda vivienda en el campo y próxima al mar, accesible en el contexto de "bonanza" económica del momento, en muchos casos aprovechando viviendas o parcelas heredadas.

3. Búsqueda de viviendas de precio más asequible en entornos rurales próximos a la ciudad de Cartagena, con crecientes precios de suelo, a pesar de que los precios del suelo en los pueblos del ENP nunca fueron especialmente bajos debido a la alta demanda y baja oferta de la zona (salvo en algunos pueblos más alejados de la ciudad de Cartagena y del mar).

4. Retorno de antiguos emigrantes que volvieron a sus antiguos pueblos una vez entraron en edad de jubilación, como se ha descrito en otras zonas rurales (Moltó Mantero et al., 2004), bajo un deseo de "búsqueda de las raíces", mayor complicidad sociovecinal y mayor tranquilidad; normalmente restaurando antiguas viviendas familiares, aunque también adquiriendo nuevos domicilios.

5. Alta demanda extranjera de vivienda en zonas cercanas al mar - pero no solo-, que se disparó en el litoral mediterráneo, siendo intenso este proceso en algunos pueblos del ENP.

Este crecimiento de la demanda de vivienda no vino sin embargo parejo de un aumento en la oferta, debido principalmente a las limitaciones de disponibilidad de suelo urbanizable que tienen los pueblos del paisaje de la zona por su condición de Espacio Natural Protegido, al contrario de algunos de los pueblos perimetrales al ámbito de protección - sobre todo los próximos a la ciudad de Cartagena- que sí vieron crecer nuevos desarrollos urbanísticos.

La falta de disponibilidad de viviendas provocó la rehabilitación de muchas antiguas viviendas, con distinto resultado en su adaptación al paisaje y la tipología constructiva tradicional. Sin embargo, este contexto también disparó una problemática importante en el paisaje rural de la zona: la proliferación de nuevas viviendas, en muchos casos ilegales (García Moreno et al., 2007). Este inconveniente actualmente tiene un carácter más residual, tal vez como consecuencia de que se logró contener fuertemente por las actuaciones coercitivas que se llevaron a cabo desde las distintas Administraciones Públicas, según aclaran algunos gestores entrevistados.

Se expandieron por tanto algunas nuevas viviendas, fundamentalmente aisladas, ocupando terreno agroforestal, sin servicios asociados de abastecimiento de agua, electricidad y/o alcantarillado; y con escaso cumplimiento de medidas de adaptación del paisaje. Ligada a la presencia de la vivienda y de manera no planificada, en algunos casos, ha continuado el desarrollo de construcciones e infraestructuras asociadas a la vivienda tales como piscinas, barbacoas, vallados, hormigonado-asfaltado de caminos, etc.

Según mencionaban algunos pobladores entrevistados, mientras que el pequeño crecimiento de los núcleos rurales ha quedado mayoritariamente destinado a familiares o antiguos habitantes de esos pueblos, la preferencia hacia la vivienda aislada respondió a las demandas de aislamiento y paisaje 
de los nuevos pobladores vacacionales, repitiéndose el proceso de "naturbanización" descrito en otros Espacios Naturales (Prados Velasco, 2006; 2012), también como síntoma del proceso de "musealización".

EN 2014 tuvo lugar un proceso participativo para la redefinición de los núcleos rurales en el ENP, proceso que fue muy bien valorado en las entrevistas por la propia población local. En este proceso, se celebraron en el territorio diversas reuniones entre técnicos de la Administración Pública y representantes vecinales, en las que se llegaron a acuerdos que cumplían parcialmente las demandas de los vecinos, sin que aparentemente supusieran consecuencias significativas en la conservación del paisaje agroforestal de la zona. Sin embargo, estos acuerdos nunca llegaron a ser trasladados oficialmente ni a la planificación ambiental ni al planeamiento urbanístico municipal.

c) La influencia del entorno urbano

El entorno urbano ha tenido una influencia clave en el desarrollo del ENP. La estructura poblacional se extiende en el paisaje como una tupida red de pequeños núcleos rurales y viviendas aisladas, formando parte del esquema radio-concéntrico clásico, en su parte Oeste, que se forma alrededor de la ciudad de Cartagena, formando parte de su espacio "rururbano", tan repetido en muchos entornos urbanos (Jiménez Olivenza et al., 2005; Cardoso et al., 2012; Lasanta Martínez et al., 2012). En este sentido, las escasas vías de comunicación que los relieves permiten generar, se distribuyen en torno a la ciudad de Cartagena y su conexión con otras ciudades del entorno.

Según se desprende de la información primaria recogida en las entrevistas, la proximidad a la ciudad de Cartagena (y en menor medida, al entorno urbano de Mazarrón o Torre Pacheco) permite, por un lado, que gran parte de la población del ENP trabaje en estos entornos urbanos o sus polos industriales, sobre todo en el de Cartagena, pero viva en los pueblos que forman parte del paisaje rural del ENP, como ha sucedido en otras zonas rurales cercanas a áreas urbanas (Moltó Mantero, 2004). Por otra parte, el acercamiento de la población rural a las ciudades tuvo también durante muchos años un efecto perverso facilitador de procesos de emigración, en la búsqueda de la población rural de mejores y más cercanos servicios.

Asimismo, la influencia de la gran ciudad va mucho más allá del aporte de empleo y actividad socioeconómica, alcanzando a las propias dinámicas del paisaje (liménez Olivenza et al., 1995) y participando del proceso de "musealización". En el caso del ENP, es muy significativo el creciente dominio de lo urbano sobre las tradiciones y cultura propias descrito por algunos habitantes locales entrevistados. También en la influencia del ideario político, tal y como detalló Herín (1982, 1990), relacionando el voto de izquierdas con la presencia de trabajadores del polo industrial de Cartagena en las zonas rurales del ENP cercanas a Cartagena, como Perín o Canteras; y el voto de derechas con otros pueblos más agrícolas del entorno del ENP. 
Además, la relación con la urbe no acaba en la ciudad de Cartagena, ya que las vías de comunicación existentes son descritas en las entrevistas como esenciales en la conexión con otros nodos urbanos de importancia en la Región, principalmente el entorno urbano de Murcia, pero no solamente. El acceso a estos otros nodos participa del proceso de "musealización" ampliando el acceso de los habitantes rurales del ENP a los recursos urbanos disponibles, al tiempo que facilitando el acercamiento de los recursos del paisaje agroforestal del ENP a un mayor número de potenciales visitantes, como ya ha sido descrito en otras zonas (Prados Velasco, 2012). En este caso, el acceso de la población rural alcanza los servicios aportados por los dos grandes focos de la Región de Murcia (Herín, 1982, 1990): la ciudad de Murcia con las funciones administrativas, comerciales y de agroindustria y, complementariamente, la ciudad de Cartagena con su dominio industrial, militar y portuario.

d) La aparición de nuevas arquitecturas frente a las agrarias tradicionales

La existencia histórica de población rural en el Espacio Natural ha ido asociada al desarrollo de viviendas que daban cobijo a la población local, además de otras construcciones anexas dirigidas fundamentalmente a los usos que les daban sustento, principalmente agrarios. En este sentido, la función de autoabastecimiento agrícola-ganadero-artesano y la habitual autoconstrucción de las viviendas ha determinado tradicionalmente tanto la distribución poblacional en el ENP como la propia tipología arquitectónica de las viviendas y las construcciones que la acompañan (Lejarraga et al., 2015).

Las fórmulas de arquitectura pública y privada y de distribución territorial han ido expresando tradicionalmente en el ENP diseños propios de soluciones populares, con utilización de recursos del paisaje. La utilización generalizada de materiales constructivos locales en estos acabados, ha supuesto tradicionalmente la uniformización y adaptación al paisaje del patrimonio arquitectónico de la zona (Martínez Bernal et al., 2015) (Figura 5). 
Figura 5. Arquitectura tradicional con cubierta a dos aguas en Torre de Nicolás Pérez (izqda.) y con cubierta plana en Los Fuentes de Galifa (dcha.)
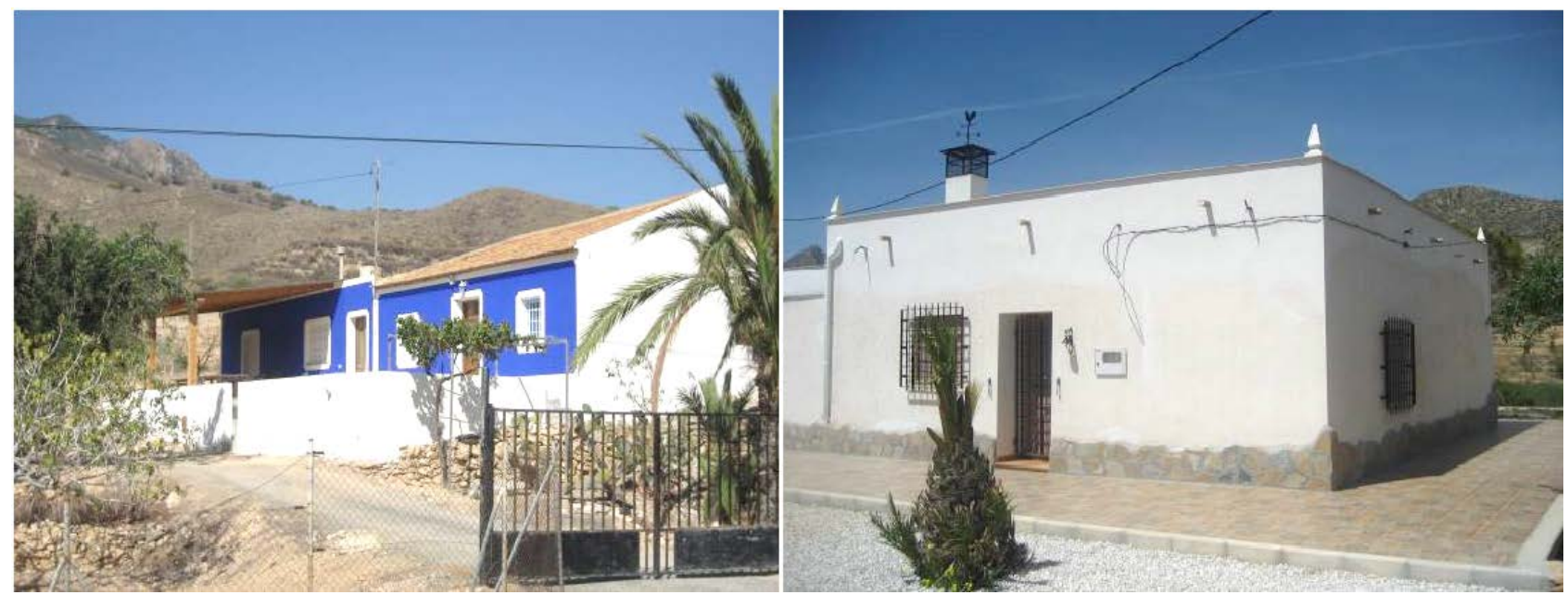

Fuente: elaboración propia

No obstante, la estructura poblacional se torna más compleja al tener que hacer frente, además de a las funciones agrícolas, a las necesidades sociovecinales y de convivencia propias de cualquier comunidad, que vino a crear dos formas tradicionalmente extendidas en la zona:

1. Asentamientos de un determinado número de viviendas distribuidas en torno a un espacio público (normalmente iglesias) que los agrupa y les confiere su carácter de vida comunitaria. Solían localizarse en el entorno de ramblas, pozos y surgencias de agua que permitían el desarrollo de aprovechamientos agrícolas de pequeñas huertas, a excepción del Portús, cuya localización costera lo asocia más a la tradición pesquera. Ejemplo de ello son los principales núcleos rurales del entorno del ENP: Galifa, Perín, Portús, Tallante, Los Puertos de Santa Bárbara...

2. Caseríos más o menos aislados, que solían generarse asociados al aprovechamiento de extensiones de terreno de diverso tamaño, y que se extienden en gran número en el ENP. En algunas ocasiones, estos caseríos aparecen también aglutinados en pequeños grupos de viviendas que se generaban vinculados a usos agrícolas, compartiendo parte de los servicios auxiliares agrarios (eras, pozos, molinos, etc.), o a la función social-religiosa en forma de pequeñas capillas asociadas a alguno de los caseríos.

Las nuevas viviendas que empezaron a proliferar en las últimas dos décadas vinieron a seguir esta antigua dicotomía vivienda aislada - vivienda agrupada, si bien ya mayoritariamente desligadas de la función agrícola tradicional y aparentemente con demandas sociales diferentes. En este sentido, los habitantes locales entrevistados diferencian la ampliación (mínima) de los núcleos rurales con nuevas viviendas, fundamentalmente para personas con lazos familiares de los actuales o antiguos pobladores de la zona; de la proliferación de viviendas aisladas (en mayor número) que ha dado 
respuesta a las nuevas demandas de viviendas como segundas residencias y viviendas vacacionales, en muchos casos para extranjeros. La preferencia por este tipo de vivienda aislada parece fundarse en la búsqueda de aislamiento y disfrute del paisaje más inalterado que demandaban los nuevos grupos sociales llegados a la zona. Sin embargo, se favorece un modelo de ordenación del territorio más desordenado y/o anárquico, tendente a la artificialización del paisaje que caracteriza su proceso de "musealización".

Asimismo, se ha tendido a un abandono generalizado de la tipología constructiva tradicional, sólo conservada por algunos pobladores más sensibles a la arquitectura local, muchos de ellos paradójicamente extranjeros. De manera general, este proceso simplificador del paisaje parece responder a la influencia de los ritmos urbanos y periurbanos relacionados con la "musealización" del paisaje, que lleva a importar por translación directa modelos constructivos disruptivos con el paisaje tradicional. También se imponen otros modelos de economización constructiva, que lleva a la utilización de viviendas prefabricadas, autocaravanas fijadas al suelo y otras soluciones similares poco compatibles con el paisaje rural del ENP. Como reconocen los gestores entrevistados, este tipo de construcciones degradantes del paisaje, se han reducido de manera importante en los últimos años, tal vez por la presión sancionadora de la administración pública.

Además, las viviendas han ido sufriendo un proceso de separación de los aprovechamientos agrarios tradicionales al tiempo que adquiriendo nuevas funcionalidades asociadas a las necesidades de sus nuevos pobladores, como ya ha sido descrito en otras zonas de la Región de Murcia (Ortín García et al., 2013). Este proceso de desagrarización del territorio, es una de las causas del abandono de parte del patrimonio hidráulico del paisaje, como antiguas norias y molinos (Berrocal Caparrós, 2007).

Según lo anterior, de una parte, las viviendas de uso vacacional presentan una gran variedad de construcciones auxiliares relacionadas con el ocio (piscinas, barbacoas, porches, garajes, etc.); que también suelen abundar en las viviendas de segunda residencia y fin de semana, aunque la vivienda en sí sea más austera. De otra parte, se encuentran las viviendas tradicionales de primera residencia, que responden a las necesidades más relacionadas con la vida cotidiana pero que también van ampliando en infraestructuras de seguridad y comodidad, en la medida de las posibilidades de sus propietarios. La presencia de estancias para el aprovechamiento agropecuario (cuadras, corrales, pozos, aljibes...) también es mayor en estas últimas al estar más ligadas a la actividad agraria, aunque ésta sea sólo como renta complementaria familiar (Figura 6). Estas diferencias entre las viviendas de primera y segunda residencia han sido también descritas en otras zonas rurales de la Región de Murcia (López Bermúdez, 2006). 
Figura 6. Contraste de construcciones anexas tradicionales y nuevas de dos viviendas ubicadas a unos cientos de metros de distancia: aljibe y abrevadero tradicionales en Campillo de Adentro (izqda.) y vivienda de reciente restauración (con barbacoa, terrazas, pérgolas, jardineras...) en la urbanización de San Ginés de La Azohía (dcha.)

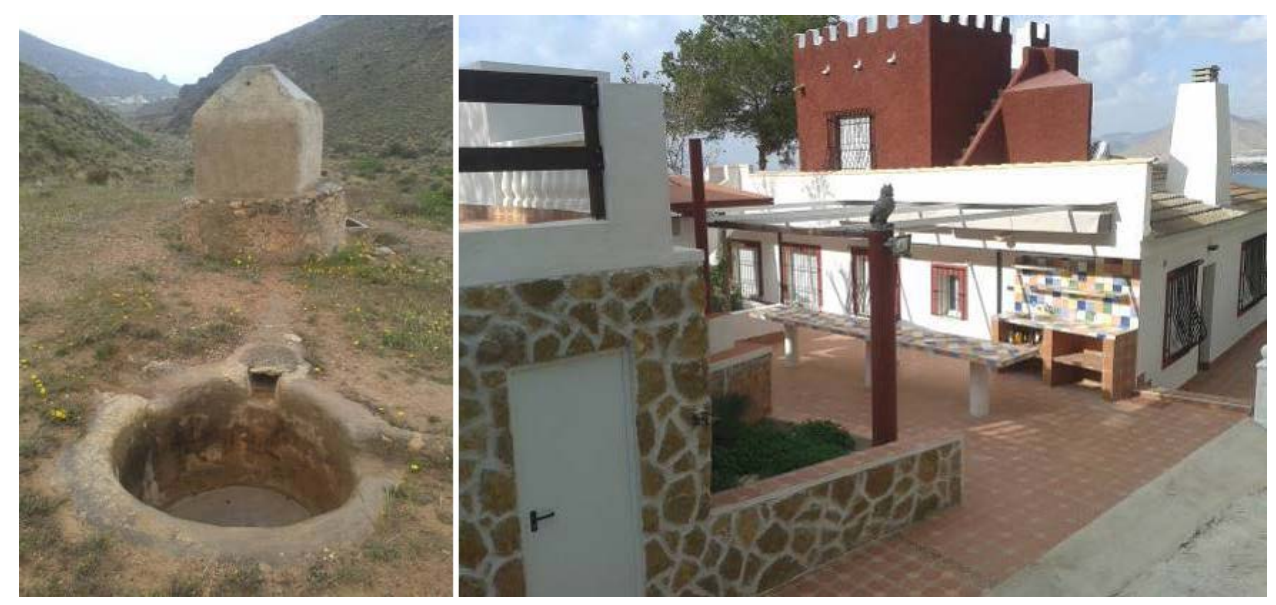

Fuente: elaboración propia

\subsection{Procesos socioeconómicos del paisaje agroforestal}

a) Abandono de cultivos y deterioro del paisaje

El paisaje rural del ENP cuenta con el cultivo de secano del almendro como el principal protagonista, en el cual se intercalan pequeñas parcelas de olivos en los rincones más húmedos y algunos pies de algarrobos en zonas más meridionales y marginales, algunos de ellos centenarios (Gil Meseguer, 2006). El almendro fue introducido en los años 60-70 sustituyendo los sembrados de cereal alternos con pies de olivo y algarrobo, que abastecían una agricultura y ganadería de subsistencia. El cultivo de secano ha tenido que adaptarse a la topografía con el acondicionamiento de bancales para retener las escorrentías superficiales y con la utilización de cultivos agrícolas tradicionales-locales adaptados a la reducida pluviometría. En las zonas próximas a ramblas (Rambla del Cañar, Rambla del Portús, Rambla del Parrillar...) el agua sirvió para la creación de algunas pequeñas huertas familiares que sobresalían entre el paisaje agrícola predominante de secano; y que ahora son escasas debido principalmente al agotamiento de los recursos hídricos de pozos y fuentes (García Moreno et al., 2007).

Los pequeños minifundios agrícolas se intercalan con las masas forestales, ocupando las zonas con menos pendiente y sirviendo de transición desde las zonas pobladas y las principales vías de comunicación hasta las zonas de monte bajo y alto. En los márgenes de las terrazas agrícolas, delimitadas por vistosas pedrizas, crece la vegetación natural sirviendo de corredor ecológico de especies vegetales, refugio de fauna y área imprescindible para el campeo de las rapaces que anidan en los roquedos escarpados (Figura 7). 
Figura 7. Cultivos de almendros entre manchas forestales en Torre de Nicolás Pérez (izqda.) y cultivos y pedrizas en proceso de abandono en Galifa (dcha.).
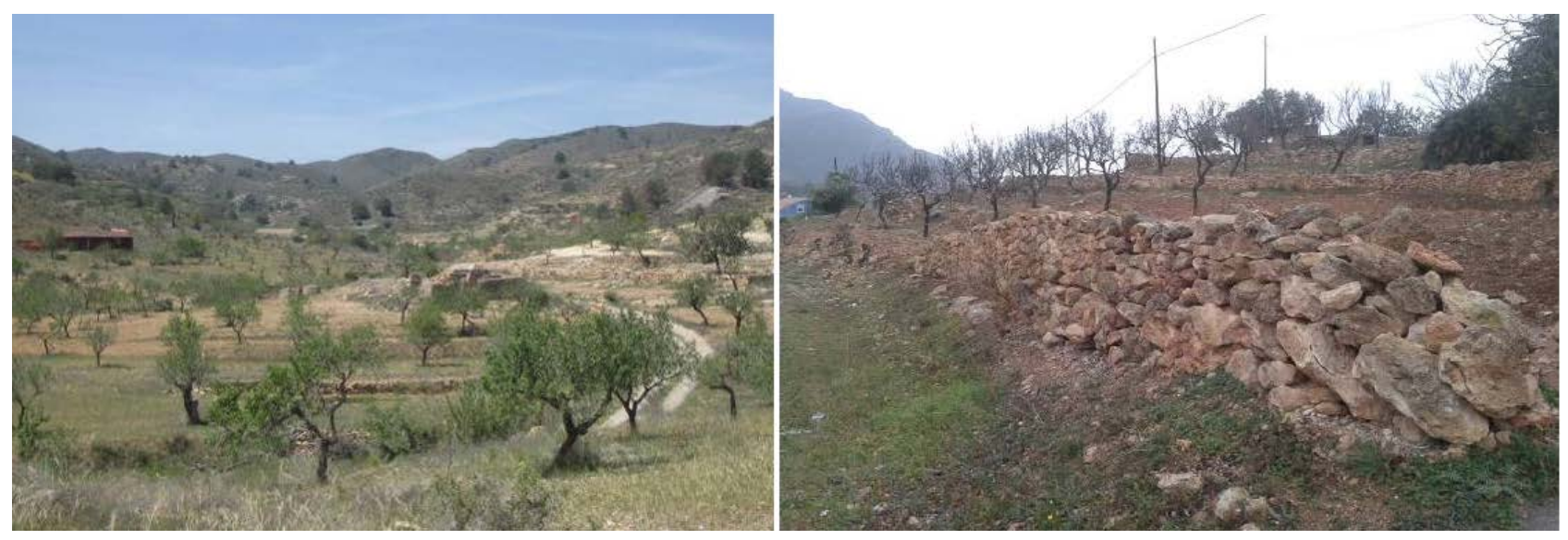

Fuente: elaboración propia

El resultado es el mosaico agroforestal característico del paisaje del ENP, que en la primavera temprana alcanza su mayor esplendor al estallar su floración blanqui-rosada, convirtiéndose en un recurso turístico de excepcional importancia y gran potencialidad para el desarrollo local (Jordán González et al., 2013).

Tal vez a causa de la irregular topografía que dificulta la intensificación agraria, no llegó -aunque quedó cerca- el agua del trasvase Tajo-Segura que hubiera transformado en agricultura de alto rendimiento gran parte del paisaje. Esta zona también quedó fuera de los recursos hídricos aportados por las desaladoras construidas en los últimos años, a pesar de que una de ellas (la de Valdelentisco) ocupa parcialmente el ámbito del ENP en su parte más occidental.

La aridez del terreno (cada vez más intensa a causa del cambio climático), la incidencia de periodos de sequía, el agotamiento de pozos y fuentes, y la falta de recursos hídricos alternativos, ha ido afectando a la disponibilidad hídrica para el mantenimiento de los cultivos. La posibilidad de atender los cultivos con dotaciones hídricas (al menos en riegos de auxilio) es una recurrente demanda de los agricultores entrevistados.

Junto a los problemas en la disponibilidad de agua de los cultivos, han podido interceder otros factores de índole interna y externa al paisaje rural del ENP. Por un lado, factores internos como la topografía irregular, la fragmentación parcelaria, la dificultad de mecanización, la escasa modernización de cultivos o la falta de alternativas de comercialización (cooperativismo, sellos de calidad o de indicativos geográficos, etc.). Por otro lado, factores externos como el aumento en la competitividad en los mercados internacionales, los bajos precios agrícolas, las políiticas comunitarias o la falta de ayudas agrarias, extrapolables a otras zonas de la Región (Cayuela Sánchez, 2015) y del Estado (Lasanta Martínez et al., 2016). 
Las entrevistas a actores del territorio han permitido constatar el abandono de los cultivos de secano por falta de rentabilidad y relevo generacional que ahondan en el riesgo de "musealización" del paisaje. En efecto, al igual que en otras zonas agrarias (Segrelles Serrano, 2013), la falta de rentabilidad del cultivo de secano en el ENP ha generado la necesidad de búsqueda de alternativas de obtención de renta, bien sea en el territorio o en la cercana ciudad de Cartagena. La explotación agrícola supone el sustento principal familiar en reducidísimos casos, convirtiéndose más en un recurso complementario para la gran parte de los pobladores originarios de la zona que poseen tierras (fundamentalmente por herencia), que son la mayoría. El trabajo de los cultivos queda relegado por tanto a su mantenimiento básico durante el tiempo libre de los propietarios, en muchos casos más como una acción quasi altruista para evitar la pérdida de las tierras familiares, tal y como reconocen la mayoría de los habitantes locales entrevistados.

En este contexto de pérdida de rentabilidad agraria, evidentemente, son pocas las inversiones en mejora de las explotaciones y reemplazo de pies deteriorados. Gran parte de los entrevistados locales se refieren al decreciente peso social que tienen valores como tradición, identidad local e identificación familiar en lo referente al mantenimiento de los cultivos familiares, sobre todo entre los más jóvenes. Esto acaba generando una tendencia a la falta de mantenimiento básico de los cultivos y a su abandono, como una causa más de la "musealización" del paisaje.

Las tierras de primer abandono son generalmente las más aisladas, las más próximas a la zona forestal y las de mayor pendiente, debido a la mayor dificultad de su laboreo. En muchas de estas zonas, la vegetación forestal va avanzando sobre una superficie agrícola de gran valor paisajístico, ecológico y cultural; aunque también recuperando zonas que tal vez nunca debieron ser roturadas por su abrupta topografía.

b) La necesaria gestión ganadera y cinegética del paisaje agroforestal

La actividad ganadera ha formado parte del paisaje del ENP La Muela, Cabo Tiñoso y Roldán desde prácticamente la ocupación humana de la zona. La posterior ocupación agrícola de áreas de eriales y montes bajos supuso la expulsión gradual de la actividad ganadera de muchos espacios agroforestales mediterráneos (Esteve Selma et al., 2015), tal y como pudo ocurrir en el ENP.

La actividad ganadera extensiva en la zona (de tipo ovino y caprino, fundamentalmente) es productora de lácteos, carne y tradicionalmente lo era de lana (Jordán González et al., 2013). Los procesos de intensificación ganadera son escasos en el ámbito del ENP, dada la práctica inexistencia de explotaciones avícolas y porcinas; al contrario que gran parte de la Región de Murcia (Gil Meseguer et al., 2001). En los últimos años, también han aparecido nuevas modalidades ganaderas en el ENP, tales como la equina o la crianza de caracoles.

La coevolución del paisaje agroforestal con la actividad ganadera pone de relieve la importancia de esta actividad en la gestión del paisaje y la conformación de las especies vegetales y animales que 
lo componen. Si bien la práctica ganadera parece estar bastante estabilizada en el ENP, también se manifiesta por parte de algunos ganaderos locales una posible falta de reemplazo generacional, que puede suponer la pérdida de esta actividad tradicional que puede contribuir en la "musealización" del paisaje.

La ganadería extensiva controlada ha sido históricamente una actividad sostenible, que puede tener efectos positivos sobre la germinación y el crecimiento de ciertas especies, además de contribuir en la prevención de incendios (mantenimiento de cortafuegos y caminos, "limpieza" de cunetas】) y favorecer la conservación de razas autóctonas, principalmente oveja segureña y cabra murcianogranaína. Sin embargo, algunos gestores manifiestan cierto deterioro de las manchas vegetales -algunas de ellas con especies vegetales protegidas - en algunas zonas del ENP, a causa del sobrepastoreo y/o el excesivo número de cabezas de ganado. Esto puede estar generando severos procesos de erosión, cambios en la composición del suelo por las deyecciones ganaderas, simplificación de los ecosistemas, reducción de la biodiversidad (por afectar en mayor medida a unas especies sobre las otras), afección directa sobre especies protegidas y generación de molestias a la fauna, de gran relevancia cuando afectan a la nidificación de especies protegidas como las rapaces del ENP. Para la ordenación de la actividad, desde la Administración se realizó un estudio de capacidad de carga ganadera del ENP (Esteve Selma et al., 2015), que calculaba la capacidad de carga máxima soportable de ganado ovino y caprino en los distintos sectores del espacio natural, con objeto de reducir la presión ganadera sobre las manchas del paisaje de mayor fragilidad.

En relación a la práctica cinegética, nunca ha existido en la zona una explotación cinegética de carácter intensivo-comercial, y ésta se gestiona más a través de sociedades y asociaciones de cazadores integradas generalmente por población local. Además, la población local entrevistada admite cierta tendencia al descenso de esta práctica en el ENP, que parece que ha sido más acusada en la zona de Campillo de Adentro que en Perín. Asimismo, sin entrar en los cuestionamientos éticos de la práctica cinegética que tantas controversias generan en la opinión pública, gestores y población local mencionan la creciente problemática de evidente incompatibilidad (en tiempo y lugar) entre la práctica cinegética y el ecoturismo, que puede formar parte de la tendencia a la "musealización" del paisaje.

En este sentido, la mayor parte de los entrevistados aceptan la posible utilidad de la caza en el control de poblaciones animales que carecen de depredadores naturales, sobre todo cuando pueden generar daños agrícolas o sobre especies vegetales protegidas, como podría ser el caso del jabalí en algún momento dado en el ENP. Sin embargo, algunos también citan los serios riesgos y graves problemas de conservación derivados de esta práctica, tales como el silvestrismo, el furtivismo, la caza excesiva, la caza en periodos reproductivos de la presa y otras especies silvestres, la amenaza frente a depredadores naturales de especies cazables como rapaces, daños 
a cultivos, contaminación de aguas y suelos por plomo, la proliferación de infraestructuras cinegéticas, etc.

c) La nueva conquista del paisaje agroforestal: el turismo

El ENP no ha destacado tradicionalmente por la afluencia masiva de un número de visitantes, lo que pudiera deberse a la dificultad de acceso a muchos de los más importantes recursos turísticos, a sus escasas infraestructuras turísticas y a la escasa promoción que ha tenido el turismo en la zona. En cualquier caso, del análisis de las entrevistas se desprende la existencia de un turismo fundamentalmente asociado al atractivo de los paisajes agronaturales y muy ligado al patrimonio cultural (sobre todo militar) del ENP, más allá del turismo de sol y playa tradicional en las zonas costeras como el Portús o La Azohía, colindante al ENP.

Las zonas con mayor afluencia de uso público se concentran en El Portús, para el uso de camping y de baño, y la batería militar de Castillitos de Cabo Tiñoso, con uso turístico-contemplativo del patrimonio militar también existe en menor intensidad en otras baterías militares del ENP. Asimismo, tanto el Monte Roldán como la Sierra de La Muela o la Rambla del Cañar reciben un alto y creciente número de visitantes para la práctica deportiva del senderismo, el BTT o la escalada. Además, ha crecido la práctica de otros deportes minoritarios como el parapente, focalizado en la zona del Portús, Garabitos y La Azohía; la espeleología, aprovechando las cuevas Sima Destapada y Sima de Hornos, en La Azohía; y las rutas en kayaks en la costa del cabo tiñoso. La práctica con quads, motocross y otros vehículos a motor, aunque existente, es excepcional por no autorizarse en el ámbito del ENP.

Asimismo, según apuntan tanto gestores como la población local, el número de visitantes parece haber crecido en los últimos años intensamente, tanto en zonas antes menos frecuentadas como el Monte Roldán, la Sierra de La Muela o la batería militar de Castillitos en Cabo Tiñoso, como en áreas con más tradición turística como el Portús. El aumento del número de visitantes ha venido acompañado del crecimiento lento, esporádico y no planificado de infraestructuras turísticas (alojamientos rurales, camping, residencias vacacionales de alquiler, restaurantes, establecimientos de turismo activo[) (Figura 8). Todo ello es un indicativo más del proceso "musealizador" del paisaje.

La imagen de calidad paisajística y de "excelencia" que se asocia dentro del imaginario colectivo a los Espacios Naturales Protegidos, supone de por sí un "efecto llamada" al ecoturismo que facilita la afluencia de visitantes a este ENP, lo que ha supuesto que el crecimiento del ecoturismo triplique al del resto del sector en toda España (Gómez-Limón García et al., 2014). En este sentido, en el aumento del turismo en el ENP pueden estar interviniendo otros factores externos tales como el incremento en la calidad de vida y la disponibilidad económica, el apetito social de exclusividad de la visita frente a la tendencia homogeneizadora del turismo masivo, la mayor demanda de servicios 
de bienestar, el crecimiento en la sensibilidad ambiental que favorece la valoración creciente de los paisajes agroforestales o la mayor consciencia de los beneficios de los Espacios Naturales sobre la salud (Múgica de La Guerra et al., 2013).

Figura 8. Ejemplos de actividades turísticas en el ENP: camping El Portús (izqda.) y venta La Muela en Galifa (dcha.)

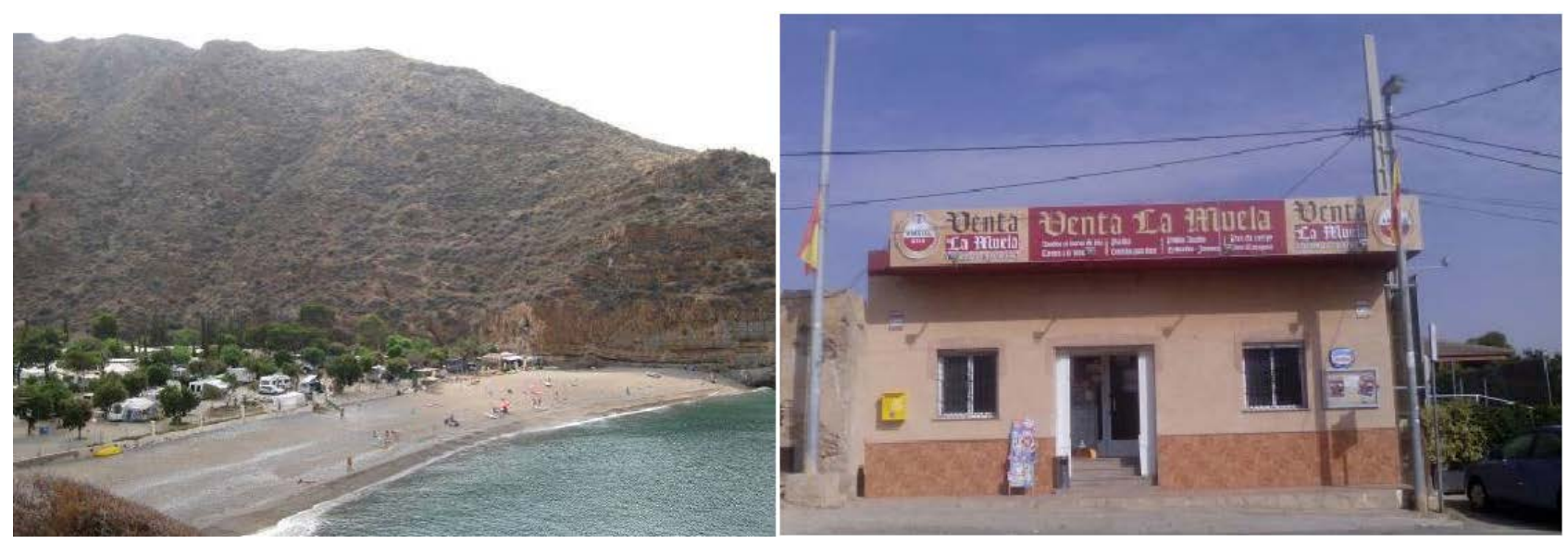

Fuente: elaboración propia

Relacionado con el incremento del turismo, aparece el crecimiento en la práctica de deportes en el medio rural y natural del ENP al que se alude frecuentemente en las entrevistas, y que ha sido descrito de manera generalizada para los Espacios Naturales (Gómez-Limón García et al., 2016). Esta práctica se muestra en la zona tanto en la forma de la práctica libre individual o grupal, como a través de carreras organizadas. En el ámbito del ENP destaca el "Burro Trail" de Perín, y la masiva "Ruta de las Fortalezas" de Cartagena, si bien existen algunas más que atraviesan parcialmente el ámbito del ENP. Como advierten los gestores en las entrevistas, la presencia de grandes pruebas deportivas en el ENP no supone únicamente la afluencia masiva de deportistas en el día de la prueba, sino un "efecto llamada" a la repetición de los recorridos de las pruebas durante todo el año y a la realización de entrenamientos en estas zonas.

Como consecuencia, los gestores describen en las entrevistas problemáticas de conservación tales como abandono de residuos, molestias a fauna por contaminación acústica (con riesgo de afectar a la nidificación de avifauna), pisoteo o arranque de vegetación (algunas de ellas especies protegidas) por visitantes y sus vehículos, compactación del suelo, inestabilidad de laderas, expolio de bienes de interés cultural, o aumento en el riesgo de incendio; entre otras. Además, en muchos casos la práctica deportiva transcurre por la noche y/o en lugares de alta sensibilidad ecológica (cumbres, áreas semivírgenes, cabos[), en los que el riesgo para la conservación de los paisajes puede ser mayor. La conflictividad con propietarios y con otros usuarios del ENP es también aludida por gestores y población local. 
Sin embargo, los gestores entrevistados describen también la puesta en marcha de acciones de compatibilización de las pruebas deportivas en el ENP, tales como la limitación del número de participantes, la prohibición de acceso de vehículos a ciertas zonas, la preferencia en la utilización de vías pavimentadas y/o marcadas, el establecimiento del inicio y fin de las pruebas en zonas urbanas, la localización de zonas de avituallamiento en áreas menos sensibles, la utilización de productos de avituallamiento sin residuos plásticos o la obligación de recogida de basuras, entre otras.

En cualquier caso, la totalidad de los entrevistados acepta que el ENP parece estar lejos de haber superado su capacidad de carga de recepción de visitantes, al menos en términos absolutos, ya que tan solo algunas zonas (Monte Roldán o Portús, por ejemplo) sí podrían presentar cierto grado de saturación en momentos esporádicos de muy alta demanda. Asimismo, el auge de la práctica deportiva se relaciona por algunos gestores como con una posible "moda" que puede haber llegado ya a su máximo, apreciando una aparente reducción de la práctica deportiva en el ENP.

La llegada de un gran número de visitantes se aprecia por los entrevistados como una gran oportunidad de desarrollo local y creación de empleo, ya descrita por otros autores (Jiménez et al., 2014); si bien actualmente la población local entrevistada no parece advertir una relación directa entre el crecimiento del turismo en el ENP y la generación de empleo, tal vez por la falta de estrategias turísticas específicas para el territorio (Garzón García et al., 2018). Además, como ya han descrito otros autores (Corbera Millán, 2016), en la zona también se menciona el efecto perverso del auge de visitas al ENP, debido a que en muchos casos los visitantes desarrollan su actividad de ocio utilizando el paisaje local como mero sustrato, de espaldas a las actividades tradicionales con las que a veces incluso entran en conflicto directo. La trivialización de la importancia de las actividades tradicionales en la confección del paisaje lleva, por un lado, a la "banalización" del paisaje local como recurso y, por otro lado, a la sobrevaloración de la invariabilidad absoluta del paisaje; como una señal más del proceso de "musealización" del paisaje.

\subsection{Procesos socioculturales y administrativos del paisaje rural}

a) El fracaso de la protección sin planificación

El paisaje rural del ENP presenta un gran número de figuras de protección (ENP, ZEPA, LIC, APFS), que sin embargo no ha sido traducido en el desarrollo de instrumentos de regulación y planificación. Esto es, el ENP cuenta únicamente con un Plan de Ordenación de los Recursos Naturales (PORN) aprobado inicialmente en el año 2006, que sin embargo no pasó el trámite final de aprobación definitiva; y además los espacios de la Red Natura 2000 (RN) carecen hasta la fecha de Plan de Gestión. Esta situación de protección "sobre papel", ya mencionada por otros autores (Santamarina et al., 2014), aparece contextualizada por muchos de los entrevistados en una 
insuficiente atención político-administrativa hacia el paisaje y sus posibilidades de desarrollo territorial, que ha dificultado su gestión y vigilancia y ha podido apoyar la dinámica del paisaje hacia su "musealización".

En efecto, aunque el Espacio Natural fue protegido por ley en 1992, la norma no delimitaba los límites del ENP ni definía su figura específica de protección. La aprobación de los espacios RN (LIC y ZEPA), en 2001 y 2002, con una delimitación clara, fue la que puso en marcha la protección efectiva de parte del ENP (el ámbito de la RN es menor que el del actual ENP). Sin embargo, para gran parte de los entrevistados, la aprobación de estos lugares RN se realizó bajo una propuesta estanca no acordada con la población local ni con una información adecuada a los propietarios afectados, lo que supuso un alto grado de rechazo vecinal debido a la transición brusca que supuso la protección en la limitación de algunas de sus actividades.

De las entrevistas se extrae que, cuando en 2006 se aprobó inicialmente el PORN que pretendía declarar el ENP como Parque Regional, la brecha abierta entre la protección del Espacio Natural y la población local volvió a acentuarse, y la oposición vecinal propició la no aprobación definitiva del PORN. A pesar de que la fase de exposición pública del plan se amplió en varias ocasiones, el procedimiento reglado recibió quejas por basarse en un documento ya cerrado, que no había sido elaborado con la participación de la población local, a través de reuniones previas, establecimiento de grupos de trabajo, etc. Además de que el PORN marcó los límites del ENP, la no demarcación expresa de los núcleos rurales y viviendas diseminadas existentes (por no estar tampoco reconocidos en su mayoría en la planificación urbanística de Cartagena) fue la mayor causa de oposición de la población local.

Los gestores entrevistados admiten las dificultades en la puesta en práctica de procesos de participación y el gran esfuerzo en tiempo y recursos humanos para su desarrollo, además de la dificultad legal-administrativa de que los acuerdos alcanzados acaben transpuestos a la normativa; tal y como fue el caso del último proceso de participación del ENP en relación a la delimitación de sus núcleos rurales. También se refieren a la confrontación de intereses entre diferentes sectores sociales y económicos, que no facilita el poder alcanzar consensos intermedios, como parece que ocurrió durante el proceso de exposición pública del PORN aprobado inicialmente. No obstante, los gestores entrevistados consideran que en los últimos años en la administración pública ha ido internalizándose la necesidad de la participación pública en la planificación y la gestión del ENP, aparentemente más por iniciativa técnica que política; y citan algunos contactos actuales con representantes vecinales.

En cualquier caso, según se extrae de las entrevistas, parece que no se consiguió trasladar adecuadamente las razones y las necesidades para la protección del ENP, ya fuera por excesivo contenido técnico de la información difundida o, sobre todo, porque no se logró trasmitir las 
oportunidades que podrían derivarse de la protección legal del ENP y que han sido detalladas por algunos autores (Romero Calcerrada et al., 1994). Por el contrario, en algunos casos han existido sectores interesados que han podido "contaminar" el mensaje con falsas amenazas e informaciones sacadas de contexto.

Asimismo, el corto desarrollo de los instrumentos de planificación ha ido acompañado de una escasa inversión económica que se ha visto reflejada en los insuficientes medios humanos con los que ha dispuesto el ENP para la realización de las necesarias tareas de vigilancia, gestión, fomento y divulgación ambiental. Según se extrae de las entrevistas, la gestión del ENP ha sido durante este tiempo bastante reducida, consistiendo principalmente en la aplicación de medidas coercitivas que evitaran la destrucción de sus valores naturales (fundamentalmente por la proliferación de viviendas ilegales y otras construcciones anexas, y, más tarde, por la no adaptación paisajística de éstas). Las escasas medidas proactivas que se han llevado a cabo, han ido más dirigidas a la contención de problemáticas de conservación (restauraciones vegetales, recuperación de especies protegidas, eliminación de especies invasoras...), a la ordenación de actividades (cierre de caminos y sendas, tratamientos forestales preventivos...) y en escasas ocasiones al fomento del desarrollo socioeconómico compatible con el ENP. La reducción en tiempo y forma de la burocracia administrativa para la autorización de actividades en el ámbito del ENP es una petición recurrente de los pobladores locales.

Las entrevistas a la población local evidencian la gran incertidumbre acerca de las regulaciones aplicables en la protección del ENP derivada de la falta de aprobación de un PORN definitivo y de un Plan de Gestión de los espacios RN, lo cual acaba traduciéndose en que muchos pobladores y agricultores locales siguen mostrándose escépticos a las políticas verdes de gestión del ENP, como también ha sido descrito en otras zonas (Sauri et al., 2006). Sin embargo, al mismo tiempo se advierte una mejora en la aceptación social del ENP, tal vez derivada del descubrimiento de las oportunidades que puede ofrecer la conservación del paisaje de la zona, de la mayor concienciación ambiental de las nuevas generaciones, así como de la propia resignación que el tiempo ha podido aportar.

\section{b) Bienes públicos de propiedad privada}

Aunque el paisaje agroforestal del ENP sea considerado un bien social aportador de amplios servicios socioambientales de carácter público, la mayor parte de la propiedad es privada. En este sentido, mientras que la explotación productivista del paisaje es perseguida (de manera loable y justificada) por la propiedad privada de las tierras, la administración pública es la garante de asegurar que ese paisaje siga aportando los servicios socioambientales que derivan de su conservación. No obstante, la función de la administración pública es aquí claramente confundida por la opinión pública, donde abunda el desconocimiento de que la mayor parte de la superficie 
de este ENP es privada, y que la protección ambiental de una superficie no implica la posibilidad de su uso libre por parte de la totalidad de la sociedad. Con las tierras agrícolas del ENP esta asociación errónea de ideas, bastante criticada en las entrevistas, está menos extendida que con las superficies forestales, tal vez porque llevan asociadas la presencia de un agricultor que las trabaja.

Por otro lado, la función reguladora de la administración pública es difícilmente aceptada por gran parte de la propiedad privada del ENP. Muchos propietarios manifiestan en las entrevistas no compartir la limitación de usos que se deriva de la protección ambiental del ENP, a pesar de que muchas de estas limitaciones existieran previamente en normativas sectoriales o en el planeamiento urbano municipal. Algunos entrevistados también creen que las limitaciones no deberían prohibir usos y actividades, sino restringirse a marcar recomendaciones para favorecer su compatibilización con el paisaje. En este sentido, la justificación de que detrás de esa regulación se encuentra el interés social, es asociada por algunos propietarios con una "apropiación" de sus tierras por parte de la administración pública. Un ejemplo claro de esto, es el rechazo de la prohibición general de construcción de nuevas viviendas.

Se muestra por tanto aquí el eterno conflicto entre el interés individual privado y el interés colectivo social, y hasta dónde deben llegar los límites del uno y otro. Al considerar como recurso el paisaje agroforestal del ENP y los elementos ambientales y culturales que lo componen, sale a colación el cuestionamiento moral de la consideración del paisaje como bien económico, y de su instrumentalización a través de las políticas de mercado. Frente a esta discusión (Leff Zimmerman, 2004), relacionada directamente con el proceso de "musealización" de paisajes como el del ENP, se expresa la ineficacia aparente de las sociedades para el mantenimiento de bienes públicos de uso comunal.

En el entorno del ENP ha funcionado muy bien el desarrollo de acuerdos de custodia del territorio con propietarios y pequeños empresarios locales, realizados por varias asociaciones entre las que destaca ECUGA (Entidad de Custodia del Territorio para la conservación del Garbancillo de Tallante). Esta asociación, que nació al amparo de un programa LIFE, ha alcanzado en el territorio un nivel de aceptación y reconocimiento social muy alto. En la aprobación de la actividad de ECUGA obtenida en las entrevistas, ha contribuido que la población local haya estado involucrada prácticamente en todo el proceso, que su difusión se haya realizado a través del "boca-oído" vecinal o que sus gestores hayan empleado esfuerzos en empatizar con los intereses de la población. De este modo, bajo el paraguas de la conservación de la especie garbancillo de Tallante (Astragalus nitidiflorus), en peligro de extinción, se ha fortalecido intensamente la identidad de pertenencia al territorio gracias a la realización de distintas actuaciones y la organización de actividades diversas.

c) Las relaciones sociales y la identidad territorial 
Las identidades territoriales que muestra la población rural del paisaje del ENP parecen relacionarse intensamente con su pertenencia al municipio y la comarca de Cartagena, en la que históricamente ha existido un acusado carácter identitario comarcal-cartagenero (Moya Méndez, 2016). Asociado a esta fuerte identificación cartagenera que se expresa en las entrevistas, aparece también una fuerte identidad nacional-española. Algunos pobladores del ENP manifiestan una escasa identificación murciana, en línea con el carácter acusado de diversidad y fragmentación con la que ha sido descrita la identidad murciana (Álvarez Munárriz, 2009).

Al mismo tiempo, es paradójico que los habitantes de los distintos núcleos rurales del ENP defiendan en las entrevistas una pertenencia territorial muy localista, ligada únicamente al pueblo en el que viven, y se sientan prácticamente ajenos de la cultura del pueblo vecino. Se identifica así una multiplicidad de mini-identidades locales de necesario - pero escaso- entendimiento las unas con las otras. La unión territorial sí ha existido sin embargo cuando aparecen intereses comunes que defender frente a la Administración.

La continua llegada de extranjeros ha venido a complicar aún más las relaciones sociovecinales de estos pueblos. Según se manifiesta en las entrevistas, los grupos de amistad que organizan estos inmigrantes suelen componerse básicamente de población extranjera y, en su día a día, los extranjeros mantienen una actividad cultural paralela, teniendo incluso locales de encuentro propios donde practican actividades foráneas en su lengua nativa.

Sin embargo, estos extranjeros también participan voluntariamente en las fiestas y tradiciones locales, aunque lo hacen "juntos pero no revueltos", o sea, en pequeños grupos de personas pertenecientes a su cultura originaria, con escaso contacto real con los pobladores "autóctonos". Asimismo, aunque los habitantes originarios de estos pueblos -también voluntariosos- invitan a los extranjeros a participar; no existe una adaptación de las actividades organizadas a las nuevas culturas que han llegado al territorio y ofrecen una participación subsidiaria más que activa.

Por otra parte, aunque en menor medida, también están los extranjeros de origen africano (principalmente marroquíes) y americano (fundamentalmente ecuatorianos y bolivianos), que suelen trabajar en la agricultura, ganadería y hostelería de la zona. Estos inmigrantes, y sobre todo los marroquíes, se asocian en las entrevistas a una escasa inserción sociocultural y participación en las actividades locales.

La asociación entre las identidades territoriales de la población local y la apropiación que de éstas puedan hacer los nuevos pobladores, se relaciona directamente con su participación en la comunidad local y la conservación de la cultura y el paisaje de la zona (Vidal i Moranta et al., 2005). En el caso del paisaje del ENP, el cambio brusco en la composición sociocultural local de las últimas décadas, ha podido derivar en una heterogeneidad de identidades territoriales y un 
debilitamiento de las identidades locales, que puede estar interviniendo en el proceso de "musealización" del paisaje.

d) Los gestores tradicionales del paisaje rural

El modelado del actual paisaje rural del Espacio Natural de La Muela, Cabo Tiñoso y Roldán, se ha definido bajo una importante presencia tradicional de la actividad humana (Figura 9). El ser humano ha sido y es el principal elemento modelador del paisaje agroforestal del Espacio Natural. La coevolución del paisaje agroforestal del ENP con el ser humano que lo gestiona, como en el resto de paisajes mediterráneos (Tello Aragay, 1999), es bastante clara.

Figura 9. Contraste entre los agricultores tradicionales (izqda.: Torre de Nicolás Pérez) y los nuevos habitantes y visitantes (dcha.: playa de El Portús)
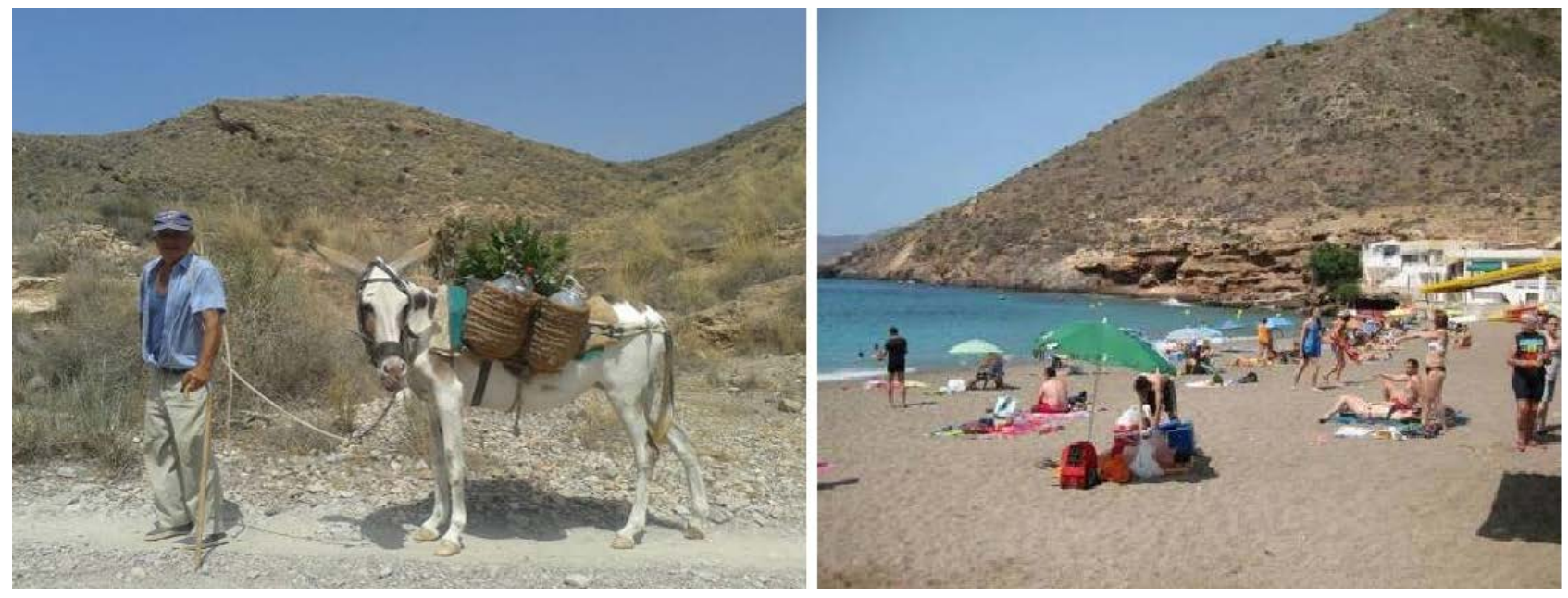

Fuente: elaboración propia

La actividad tradicional del ser humano está detrás del mantenimiento de estos paisajes, cuya existencia determina la conservación de gran parte de los valores ambientales del Espacio Natural. Esto es, muchas de las especies (algunas de ellas protegidas) dependen para su desarrollo del mantenimiento de la actividad rural en el ENP. Ejemplo de ello son las numerosas especies rapaces que utilizan los campos agrícolas del ENP como zona de alimentación; o la especie vegetal garbancillo de Tallante (Astragalus nitidiflorus), en peligro de extinción, que utiliza como hábitat potencial algunos cultivos de almendros del ENP (Jordán González et al., 2013).

Por otra parte, cabe mencionar la importancia de la mujer en la gestión del paisaje agroforestal del ENP que se extrae de las entrevistas; ya no sólo por su contribución en el trabajo agrícola, sino también bajo el desarrollo de tareas "invisibles" como la realización del trabajo doméstico, el mantenimiento de la vida familiar, o la participación en la vida sociovecinal y la transmisión de la cultura y tradiciones locales. Como en otras áreas agrícolas tradicionales donde la incidencia del 
patriarcado es aún mayor, también en la Región de Murcia (Cayuela Sánchez, 2015), la invisibilidad del trabajo de la mujer está aún muy presente en las sociedades locales del ENP.

En cualquier caso, la mayor parte de los entrevistados coinciden en que la protección del paisaje agroforestal no tiene por qué estar enfrentada con la producción agropecuaria, siempre que ésta se realice en términos de sostenibilidad socioambiental (y económica) y compatibilidad con la conservación de los valores del paisaje, como también han señalado otros autores (Lasanta Martínez et al., 2013; Segrelles Serrano, 2013). Esta estrategia suele encontrar en el aprovechamiento agropecuario tradicional la base metodológica para su desarrollo, mencionándose además nuevas oportunidades de acción en alternativas como la agricultura ecológica y la aplicación de certificados de gestión de la calidad.

En oposición al proceso de "musealización", la actividad gestora del paisaje, o sea, la actividad agropecuaria y la vida rural de los pueblos del ENP, "construye" el paisaje activando las funciones ambientales y socioeconómicas que aporta (Otero et al., 2013; Silva Pérez et al., 2017), siendo también base de otras alternativas económicas como el ecoturismo, entre otros (liménez Olivienza, 1994). La participación de la población local en el moldeado del paisaje ha sido fundamental a lo largo de su evolución, y parece justa y necesaria la implicación de las comunidades locales para la conservación de este paisaje que es resultado de su actividad (Elías, 2008; Magaña et al., 2008).

e) El papel de los nuevos pobladores.

Los nuevos habitantes llegados en los últimos veinte-treinta años son en su mayoría propietarios de segunda vivienda que no suelen ejercer, salvo en casos excepcionales, una gran actividad directa en el paisaje agroforestal -más allá de su residencia-. Tampoco los nuevos pobladores residentes como primera vivienda generan una gran actividad por tener otros empleos principales (generalmente fuera del ENP) y/o por la disociación hacia las prácticas tradicionales de la zona. Además, otros muchos son extranjeros, lo cual presupone de partida una diferencia cultural (y lingüística, en la mayoría de los casos) que altera aún más las estructuras antropológicas tradicionales.

Igualmente, las entrevistas muestran una preferencia de los nuevos pobladores hacia paisajes poco intervenidos por el ser humano, a diferencia de la tendencia hacia paisajes productivistas de los habitantes originarios, que ya había sido detectada en otras zonas (Claval, 2005; Natori et al., 2008; Walker et al., 2008). Esto contrasta con el mayor conocimiento práctico del funcionamiento de las dinámicas tradicionales del paisaje cultural de la zona que poseen los viejos pobladores, tal y como detectaron otros trabajos (Lasanta et al., 2015), al tiempo que genera diferentes demandas entre unos y otros grupos sociales.

En este sentido, en las entrevistas se han mencionado ciertos "conflictos" de los nuevos usos del paisaje con la actividad agropecuaria (Figura 10). Ejemplos de ello podrían ser algunas quejas con 
los olores de las explotaciones ganaderas, con el pastoreo en zonas naturales, acerca de tratamientos forestales preventivos realizados, con la práctica de la caza en zonas utilizadas para el uso públicon; y de manera muy importante, con el uso de propiedades privadas para actividades de uso público no autorizadas.

Figura 10. Muestras de conflictos del creciente uso público con la propiedad (izqda.: vallado del camino de acceso a La Muela)

y la conservación (señal del ENP deteriorada en el collado del Monte Roldán)
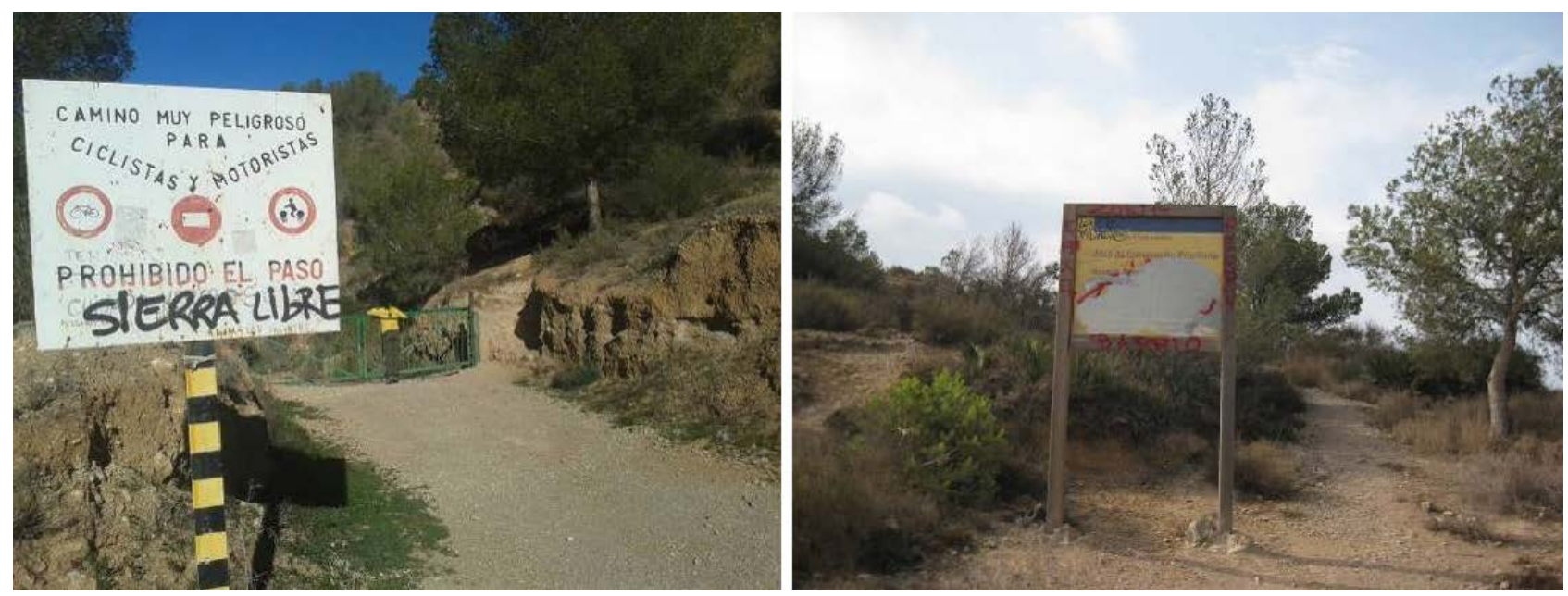

Fuente: elaboración propia

Esto se debe a que, en algunas ocasiones, los servicios del paisaje que persiguen los nuevos pobladores son contradictorios con las funcionalidades primarias tradicionalmente presentes en las zonas rurales del ENP. Los visitantes "urbanitas" defienden una visión distorsionada e idealizada de su propio medio rural, en el que buscan aquello que les parece atractivo; desatendiendo o incluso despreciando aquellos elementos del medio rural que no entran dentro de los estereotipos de naturalidad, aislamiento y tranquilidad del paisaje; no siendo un proceso único del paisaje rural del ENP (Moltó Mantero et al., 2004).

En cualquier caso, estas nuevas demandas al paisaje agroforestal, junto con el abandono paulatino de la práctica agropecuaria, parecen ser parte de un proceso generalizado en las zonas rurales (Etxezarreta Zubizarreta, 1988; Antrop, 2006) hacia la "musealización" del paisaje agroforestal, que cada vez se identifica en mayor medida como "un lugar para vivir, pero no para ganarse la vida", que declaraba uno de los entrevistados. El paisaje podría perder por tanto su carácter tradicional resultado de la coevolución del territorio y el ser humano, para convertirse en una imagen estanca en la que realizar actividades de ocio. La subsistencia de la actividad humana (y agropecuaria) sostenible parece por tanto necesaria para la conservación de los paisajes que dan sustento a estas otras actividades que son demandadas por los nuevos pobladores. 


\section{Conclusiones.}

El cambio en las sociedades locales ha traído consigo la llegada de nuevas demandas más "aculturales" del paisaje rural del ENP La Muela, Cabo Tiñoso y Roldán, que se enfrentan al mantenimiento de las prácticas socioculturales tradicionales "constructoras" del paisaje local. Los procesos territoriales y arquitectónicos, socioeconómicos y socioculturales identificados en el territorio muestran una tendencia a la "musealización" de un paisaje cada vez más estanco y carente de las prácticas que han conformado el paisaje expuesto en forma de "isla-museo" al aire libre:

- En lo referido a los procesos territoriales y arquitectónicos, la llegada de nuevos habitantes al territorio, muchos de ellos extranjeros influye de manera clave debido a su pretensión de habitar la zona rural (en forma de vivienda dormitorio de la ciudad de Cartagena o de residencia vacacional) en lugares más aislados, ansiando paisajes despojados de la actividad humana que los ha modelado. La distinta funcionalidad que los nuevos habitantes atribuyen a sus viviendas, provoca la aparición de nuevas tipologías arquitectónicas y nuevas construcciones auxiliares (piscinas, barcacoas, etc.) más desligadas de la vida cotidiana y el aprovechamiento agropecuario.

- En relación a los procesos socioeconómicos, el gran incremento no planificado en el número de visitantes se ha desarrollado al margen o incluso en conflicto directo con las actividades tradicionales locales, desatendiendo la acción humana sobre el paisaje tradicional y considerando el territorio como mera base para sus actividades de ocio. Por otra parte, el desligamiento de la población local de la actividad agraria por falta de rentabilidad económica y la falta de relevo generacional está provocando el abandono de los cultivos de secano y la práctica ganadera extensiva tradicionalmente modeladora del paisaje local.

- Respecto a los procesos socioculturales y administrativos, la falta de acción público-administrativa aviva el conflicto social entre la defensa del interés colectivo social de la conservación del paisaje, frente al interés individual privado de los propietarios. En contraposición a los pobladores locales "autóctonos", habituales gestores del paisaje, los nuevos habitantes ejercen escasamente actividad laboral y/o vida sociocultural en la zona, no participando de las acciones que permiten mantener activas las funciones mantenedores del paisaje local.

La incidencia de estos procesos tendentes a la "musealización" del paisaje genera conflictos de intereses y oportunidades, que han de ordenarse para asegurar el mantenimiento de los paisajes vivos que aún posee el ENP. En el entendimiento necesario de nuevos y tradicionales usos, a través de la regulación de unas y otras actividades, parece encontrarse el difícil equilibrio para su conservación: 
- En relación a los procesos territoriales y arquitectónicos, el control de las construcciones ilegales parece actualmente estar contenida, si bien es necesario mantener la inversión en vigilancia y disciplina urbanística. La histórica demanda vecinal de crecimiento de los núcleos rurales del ENP debe ser atendida, alcanzando un acuerdo con los vecinos de la zona compatible con la conservación de los valores del paisaje. La tipología arquitectónica tradicional debe fomentarse con el establecimiento de planes específicos de integración de viviendas, dando respuesta a las actuales demandas de construcciones auxiliares de los nuevos pobladores.

- Con respecto a los procesos socioeconómicos, se proponen distintos instrumentos dirigidos a compensar económicamente los servicios socioambientales de la actividad agropecuaria, generando un tejido productivo sostenible en el tiempo; así como a favorecer el reemplazo generacional, el fomento del asociacionismo-cooperativismo, la producción ecológica y de calidad, la diversificación de actividades y el desarrollo de agroindustrias compatibles. La tendencia de la gestión del uso público en el ENP debe dirigirse en forma de estrategia pública hacia la creación de una red sólida de ecoturismo que ponga en valor el paisaje, los recursos patrimoniales y los productos locales; asegurando que el aporte de servicios e infraestructuras turísticas alcanza las poblaciones rurales. En este sentido, la realización de actividades masivas que utilizan el paisaje como mero soporte, también las deportivas, deben tender a ordenarse (en frecuencia, lugar y tiempo), contemplándose como experiencias excepcionales.

- En lo referido a los procesos socioculturales y de gestión, los conflictos existentes entre la conservación del paisaje y los distintos usos y la propiedad privada, plantea la necesidad de una adecuada planificación. En este sentido, es esencial la participación de los sectores implicados y la población local, bajo un marco de intercambio de información más fluido, y a través de interlocutores cercanos, tales como las entidades de custodia o las asociaciones locales. También se plantea la necesidad de evitar el abandono de la población local, favorecer el protagonismo de la mujer, fortalecer las identidades locales y facilitar la inserción sociocultural y laboral de los nuevos pobladores.

Agradecimientos: A los entrevistados: población local y técnicos y Agentes Medioambientales de la Dirección General del Medio Natural de la Región de Murcia.

Declaración responsable: Las/os autoras/es declaran que no existe ningún conflicto de interés en relación con la publicación de este artículo. El primer autor, José Martínez Sánchez, ha sido el encargado de desarrollar la revisión bibliográfica, el análisis básico de datos, la realización de entrevistas, el análisis de entrevistas, la evaluación de resultados y la elaboración de conclusiones. La segunda autora, Laura Martínez-Carrasco Martínez, ha sido la encargada de revisar el procedimiento metodológico, la evaluación de resultados y la elaboración de conclusiones. 


\section{Bibliografía}

Álvarez Munárriz, L. (2009). La identidad personal en la Región de Murcia. Revista Murciana de Antropología, 16, 309-324. Retrieved from http://revistas.um.es/rmu/article/view/210371

Antrop, M. (2005). Why landscapes of the past are important for the future? Landscape and Urban Planning, 70, 21-34. http://dx.doi.org/10.1016/j.landurbplan.2003.10.002

Antrop, M. (2006). Sustainable landscapes: contradiction, fiction or utopia? Landscape and Urban Planning, 75, 187-197. http://dx.doi.org/10.1016/j.landurbplan.2005.02.014

Berrocal Caparrós, M.C. (2007). Sistemas tradicionales de extracción de agua en la pedanía de Galifa. Revista murciana de antropología, 14, 283-300. Retrieved from http://revistas.um.es/rmu/article/view/107941

Bowen, S., \& Master, K. (2011). New rural livelihoods or museums of production? Quality food initiatives in practice. Journal of Rural Studies, 27(1), 7382. http://dx.doi.org/10.1016/j.jrurstud.2010.08.002

Cardoso, M.M., \& Fritschy, B.A. (2012). Revisión de la definición del espacio rururbano y sus criterios de delimitación. Contribuciones Científicas, 24, 27-39. Retrieved from http://gaea.org.ar/contribuciones/CONTRIBUCIONES_2012/4.GAEA\%20CONTRIBUCIO NES_2012_CARDOSO.pdf

Cayuela Sánchez, S. (2015). Agricultura murciana y modos de vida en el contexto europeo. Un acercamiento socio-antropológico (Doctoral dissertation, Universitat Rovira i Virgili, Tarragona, Spain). Retrieved from http://hdl.handle.net/10803/306267

Celdrán Iniesta, J.A. (2001). Singularidad de los movimientos migratorios de Cartagena (19881999). Espacio, Tiempo y Forma, VI(14), 75-94.

http://dx.doi.org/10.5944/etfvi.14.2001.2582

CESIS (Consejo Económico Sindical Interprovincial del Sureste) (1970). La transformación socioeconómica del Campo de Cartagena inducida por el trasvase Tajo-Segura. Murcia: CESIS.

Claval, P. (2005). Reading the rural landscapes. Landscape and Urban Planning, 70, 919. http://dx.doi.org/10.1016/j.landurbplan.2003.10.014

Cobos Rodríguez, L.M., Mata Almonte, E., Lagóstena Barrios, L.G., Aladro-Prieto, J.M., \& Martín Gutiérrez, E. (2014). El paisaje cultural del viñedo de Jerez como Museo territorio. RdM. Revista de Museología: Publicación científica al servicio de la comunidad museológica, 60, 95-104. Retrieved from https://www.museologia.net/producto/revista-de-museologia-no-60-digital/

Corbera Millán, M. (2016). El paisaje, su patrimonialización y el beneficio económico. Investigaciones Geográficas, 65, 09-24. http://dx.doi.org/10.14198/INGEO2016.65.01 
Elías, L.V. (2008). Paisaje del viñedo: patrimonio y recurso. PASOS. Revista de Turismo y Patrimonio Cultural, 6(2), Retrieved from http://www.pasosonline.org/es/articulos/288-paisaje_del_viedo_patrimonio_y_recurso

Esteve Selma, M.A., Montoya Bernabéu, P., Miñano Martínez, J., \& Baños González, I. (2015). Establecimiento de la capacidad de carga ganadera en el Espacio Natural La Muela, Cabo Tiñoso y Roldán. Murcia: Consejería de Agricultura y Agua de la Región de Murcia (inédito).

Etxezarreta Zubizarreta, M. (Ed.) (1988). Desarrollo Rural Integrado. Madrid: Ministerio de Agricultura, Pesca y Alimentación.

García Moreno, P., \& Sánchez Balibrea, J.M. (2007). Las norias de tiro en la rambla del Cañar y Rincón de Tallante (Sierra de Cartagena), testimonios de un paisaje del agua hoy casi olvidado. Revista murciana de antropología, 14, 199-210. Retrieved from http://revistas.um.es/rmu/article/view/107851

García Ruiz, J. M., \& Lasanta Martínez, T. (2018). El Pirineo Aragonés como paisaje cultural. Pirineos, 173, e038. http://dx.doi.org/10.3989/pirineos.2018.173005

Garzón García, R., \& Ramírez López, M. L. (2018). Las áreas protegidas como territorios turísticos: Análisis crítico a partir del caso de los parques naturales de la Sierra Morena andaluza. Cuadernos de Turismo, 41. http://dx.doi.org/10.6018/turismo.41.327021

Gil Meseguer, E., \& Gómez Espín, J.M. (2001). La ganadería de la región de Murcia en el periodo 1960-2000. Respuestas ganaderas a las nuevas situaciones de producción y mercado de productos agropecuarios en la Unión Europea. Papeles de Geografía, 34, 163-190. Retrieved from http://revistas.um.es/geografia/article/view/47121

Gil Meseguer, E. (2006). Los paisajes agrarios de la Región de Murcia. Papeles de Geografía, 43, 19-30. Retrieved from http://revistas.um.es/geografia/article/view/43521

Gómez-Limón García, J.A., Moyano, E., Vera-Toscano, E., \& Garrido, F. (2007). Actitudes y percepciones sociales sobre la multifuncionalidad agraria: El caso de Andalucía. Revista de estudios regionales, $80,71-101$. Retrieved from

http://www.revistaestudiosregionales.com/documentos/articulos/pdf1021.pdf

Gómez-Limón García, J., \& García Ventura, D. (2014). Capacidad de acogida de uso público en los espacios naturales protegidos. Madrid: Organismo Autónomo Parques Nacionales (OAPN). Retrieved from hitp://www.magrama.gob.es/es/parques-nacionalesoapn/publicaciones/capacidad-acogida_tcm7-340830.pdf 
Gómez-Limón García, J., \& Martínez Alandi, C. (2016). Guía de buenas prácticas para el desarrollo de carreras por montaña en espacios naturales protegidos. Madrid: EUROPARCEspaña. Retrieved from

http://www.redeuroparc.org/system/files/shared/Publicaciones/EUROPAC_Manual12.pdf

Herín, R. (1982). Los espacios sociopolíticos de las ciudades españolas: el ejemplo de Cartagena y Murcia. Áreas, 2, 103-150. Retrieved from

http://revistas.um.es/areas/article/download/82651/79701

Herín, R. (1990). Comportamientos electorales y clases sociales: el ejemplo de Murcia (España). Papeles de geografía, 6, 143-155. Retrieved from

http://revistas.um.es/geografia/article/view/43241

Hernández Hernández, M. (2009). El paisaje como seña de identidad territorial: valoración scoial y facto de desarrollo, ¿utopía o realidad? Boletín de la Asociación de Geógrafos Españoles, 49, 169-183. Retrieved from

http://www.age-geografia.es/ojs/index.php/bage/article/view/780/703

Jiménez Herrero, L.M.; Leiva, A., Castañeda, S., García, G. Landa, L., \& López, I. (2014). Empleo verde en una economía sostenible. Madrid: Observatorio de la Sostenibilidad en España y Fundación Biodiversidad. Retrieved from

http://empleaverde.es/sites/default/files/informe_empleo_verde.pdf

Jiménez Olivencia, Y. (1994). Relaciones entre turismo y agricultura en zonas rurales de montaña: el caso de la Alpujarra granadina. In F. Fourneau \& A. M. García Lorca (Coords.), Desarrollo regional y crisis del turismo en Andalucía: Actas del simposio hispano-francés (pp. 171-185). Almería: Instituto de Estudios Almerienses. Retrieved from http://www.dipalme.org/Servicios/Anexos/anexosiea.nsf/VAnexos/IEA-drta-c8/\$File/drtac8.pdf

Jiménez Olivencia, Y., \& Martín-Vivaldi Caballero, M.E. (1995). La aglomeración urbana granadina y la transformación del paisaje del sector sur de la vega. Anales de Geografía de la Universidad Complutense, 15, 409-420. Retrieved from

https://revistas.ucm.es/index.php/AGUC/article/view/AGUC9595220409A

Jordán González, E., Martínez Rivera, R., Martínez González, R., \& Cava Miñano, M. (2013). Manual de Custodia del Territorio para la Conservación del Garbancillo de Tallante. Cartagena: Universidad Politécnica de Cartagena. Retrieved from http://repositorio.upct.es/bitstream/handle/10317/4576/isbn9788494198809.pdf? seque nce=1\&isAllowed=y 
Lasanta Martínez, T., \& Errea, M. P. (2012). Homogeneización y fragmentación en el paisaje rururbano de Logroño. Zubía, 30, 7-28. Retrieved from: http://hdl.handle.net/10261/66430

Lasanta Martínez, T., Arnáez-Vadillo, J., Ruiz Flaño, P., \& Lana-Renault, N. (2013). Los bancales en las montañas españolas: un paisaje abandonado y un recurso potencial. Boletín de la Asociación de Geógrafos Españoles, 63, 301-322. http://dx.doi.org/10.21138/bage.1616

Lasanta Martínez, T., \& Pascual Bellido, N.E. (2015). Percepción y valoración del proceso de revegetación por los actores del territorio: un estudio preliminar en el Sistema Ibérico. Documents d'Anàlisi Geogràfica, 61(1), 113-134. http://dx.doi.org/10.5565/rev/dag. 158

Lasanta Martínez, T., Carlos Inarejos, V., Arnáez, J., Pascual Bellido, N., \& Ruiz-Flaño, P. (2016). Evolución del paisaje vitícola en La Rioja (2000-2015): un análisis del papel de los programas de reconversión y reestructuración del viñedo. Investigaciones Geográficas, 66, 925. http://dx.doi.org/10.14198/INGEO2016.66.01

Leff Zimmerman, E. (2004). Racionalidad ambiental. La reapropiación social de la naturaleza. México: Siglo XXI Editores. Retrieved from http://ru.iis.sociales.unam.mx/jspui/handle/IIS/4937 Lejarraga, M., Castiñeira, E., \& Gutiérrez, B. (2015). Tipologías constructivas tradicionales en el Espacio Natural de la Sierra de Muela, Cabo Tiñoso y Roldán. In Actas del IV Congreso Nacional de Etnografía del Campo de Cartagena (pp. 120-141). Cartagena, October 22-24.

López Bermúdez, J.A. (2006). La transformación del paisaje en el regadío tradicional de la huerta de Mula. Papeles de Geografía, 44, 59-72. http://dx.doi.org/10.1016/S01692046(98)00067-X

Magaña Ochoa, J., \& Rojas Trejo, B.G. (2008). El paisaje cultural como elemento de patrimonialización: el caso de Vega de Pas, Cantabria, España. Revista LiminaR, VI(1), 83-97. Retrieved from http://ref.scielo.org/253xf5

Mander, U., \& Jongman, R. H. G. (1998). Human impact on rural landscapes in central and northern Europe. Landscape and Urban Planning, 41, 149153. http://dx.doi.org/10.1016/S0169-2046(98)00067-X

Martínez Bernal, L., \& Almela Legorburu, I. (2015). A los pies de la Sierra de la Muela: aspectos constructivos de la vivienda tradicional y propuestas de actuación (pp. 108-119). In Actas del IV Congreso Nacional de Etnografía del Campo de Cartagena (pp. 108-119). Cartagena, October, 22-24.

Mata Olmo, R. (2004). Agricultura, paisaje y gestión del territorio. Polígonos. Revista de Geografía, 14, 97-137. http://dx.doi.org/10.18002/pol.v0i14.492 
Mata Olmo, R. (2008). El paisaje, patrimonio y recurso para el desarrollo territorial sostenible: conocimiento y acción pública. Arbor: Ciencia, pensamiento y cultura, 729, 155172. http://dx.doi.org/10.3989/arbor.2008.i729.168

Moltó Mantero, E., \& Hernández Hernández, M. (2004). La funcionalidad de los medios rurales en las sociedades urbanas. Investigaciones geográficas, 34, 63-76. Retrieved from https://www.investigacionesgeograficas.com/article/view/2004-n34-la-funcionalidad-de-losmedios-rurales-en-las-sociedades-urbanas/pdf

Moltó Mantero, E., \& Hernández Hernández, M. (2016). Estrategias de adaptación a los nuevos tiempos en el olivar valenciano. El caso de la montaña de Alicante. In A.R. Ruiz Pulpón, M.A. Serrano de la Cruz Santos-Olmo \& J. Plaza Tabasco (Coords.), Treinta años de Política Agraria Común en España: Agricultura y multifuncionalidad en el contexto de la nueva ruralidad (pp. 111124). Ciudad Real: Asociación de Geógrafos Españoles (Grupo de Geografía Rural). Retrieved from https://dialnet.unirioja.es/descarga/libro/660685.pdf

Moreira, F., Queiroz, A.I., \& Aronson, J. (2006). Restoration principles applied to cultural landscapes. Journal for Nature Conservation, 14(3-4), 217224. http://dx.doi.org/10.1016/j.jnc.2006.05.007

Moya Méndez, A. (2016). Identidad cartagenera: ¿̇mito o realidad? La Razón Histórica, 32, 157167. Retrieved from

https: / / www.revistalarazonhistorica.com/app/download/10498298598/LRH+32.12.pdf?t=1461 $\underline{153874}$

Múgica de La Guerra, M., Muñoz Santos, M., \& Puertas Blázquez, J. (2013). Salud y áreas protegidas en España. Identificación de los beneficios de las áreas protegidas sobre la salud y el bienestar social. Aplicación de casos prácticos en la sociedad. Madrid: EUROPARC España. Retrieved from http://www.mapama.gob.es/es/ceneam/recursos/pag-web/salud-areasprotegidas-espana.aspx

Natori, Y., \& Chenoweth, R. (2008). Differences in rural landscape perceptions and preferences between farmers and naturalists. Journal of Environmental Psychology, 28, 250267. http://dx.doi.org/10.1016/j.jenvp.2008.02.002

Ortín García, J., \& Cano Fuentes, G. I. (2013). Territorio, población y vivienda en la Región de Murcia 2001-2011. Papeles de geografía, 57-58, 209-223. Retrieved from http://revistas.um.es/geografia/article/view/191341/158031

Otero, I., Boada, M., \& Tàbara, J.D. (2013). Social-ecological heritage and the conservation of Mediterranean landscapes under global change. A case study in Olzinelles (Catalonia). Land Use Policy, 30(1), 25-37. http://dx.doi.org/10.1016/j.landusepol.2012.02.005 
Padró Werner, J. (2002). Territorio y gestión creativa del patrimonio cultural y natural. Ábaco: Revista de cultura y ciencias sociales, 34, 55-60.

Paquettea, S., \& Domon, G. (2003). Changing ruralities, changing landscapes: exploring social recomposition using a multi-scale approach. Journal of Rural Studies, 19, 425444. http://dx.doi.org/10.1016/S0743-0167/03)00006-8

Pedroli, G.B.M., Van Elsen, T.H., \& Van Mansvelt, J.D. (2007). Values of rural landscapes in Europe: inspiration or by-product? NJAS - Wageningen Journal of Life Sciences, 54(4), 431447. http://dx.doi.org/10.1016/S1573-5214(07)80014-5

Prados Velasco, M.J. (2006). Los parques naturales como factor de atracción de la población. Un estudio exploratorio sobre el fenómeno de la naturbanización en Andalucía. Cuadernos geográficos de la Universidad de Granada, 38, 87-110. Retrieved from http://revistaseug.ugr.es/index.php/cuadgeo/article/view/1583

Prados Velasco, M.J. (2012). Naturbanización y patrones urbanos en los parques nacionales de Andalucía. Boletín de la Asociación de Geógrafos Españoles, 60, 1944. http://dx.doi.org/10.21138/bage. 1497

Reynard, E., \& Giusti, C. (2018). The Landscape and the Cultural Value of Geoheritage. In E. Reynard \& J. Brilha (Coord.), Geoheritage: Assessment, Protection, and Management (pp. 147166). Amsterdam: Elsevier. http://dx.doi.org/10.1016/B978-0-12-809531-7.00008-3

Roca, Z., \& De Nazare Oliveira-Roca, M. (2007). Affirmation of territorial identity: A development policy issue. Land Use Policy, 24, 434-442.

http://dx.doi.org/10.1016/j.landusepol.2006.05.007

Roca, Z. (2009). Landscapes, identities and development. Eighth Council of Europe Meeting of the workshops for the implementation of the European Landscape Convention: Landscape and driving forces, October 8-9, Malmö/Alnarp, Sweden. Retrieved from https://rm.coe.int/1680489509

Rodríguez Alonso, R., \& Hernández Aja, A. (2013). El litoral como espacio productivo. El caso de Cartagena. In Actas de la XXXIX Reunión de Estudios Regionales, November 21-22, Oviedo. Retrieved from http://old.reunionesdeestudiosregionales.org/Oviedo2013/htdocs/pdf/p648.pdf

Romero Calcerrada, R., \& Martínez-Vega, J. (2003). Repercusión de los espacios naturales protegidos en la economía rural española. Revista Serie Geográfica, 11, 41-60. Retrieved from http://hdl.handle.net/10261/10884

Santamarina Campos, B., Vaccaro, I. \& Beltrán Costa, O. La patrimonialización de la naturaleza: génesis, transformaciones y estado actual. Arxius de Ciències Socials, 30, 87-98. Retrieved from http://roderic.uv.es/handle/10550/43483 
Santos y Ganges, L. (2003). Las nociones de paisaje y sus implicaciones en la ordenación. Ciudades: Revista del Instituto Universitario de Urbanística de la Universidad de Valladolid, 7, 4168. http://dx.doi.org/10.24197/ciudades.07.2002.41-68

Saurí, D., \& Boada, M. (2006). Sostenibilidad y cultura campesina: Hacia modelos alternativos de desarrollo rural. Una propuesta desde Cataluña. Boletín de la Asociación de Geógrafos Españoles, 41, 315-328. Retrieved from

https://www.age-geografia.es/ojs/index.php/bage/article/view/2002

Serrano Giné, D. (2007). Paisaje y políticas públicas. Investigaciones Geográficas, 42, 109123. http://dx.doi.org/10.14198/ingeo2007.42.05

Segrelles Serrano, J.A. (2013). Conservación ambiental y aprovechamiento agropecuario: el caso del Parque Natural Agrario Los Carrizales (Elche). Boletín de la Asociación de Geógrafos Españoles, 62, 295-316. http://dx.doi.org/10.21138/bage.1579

Silva Pérez, R. (2009). Agricultura, paisaje y patrimonio territorial. Los paisajes de la agricultura vistos como patrimonio. Boletín de la Asociación de Geógrafos Españoles, 49, 309-334. Retrieved from http://www.age-geografia.es/ojs/index.php/bage/article/view/786/709

Silva Pérez, R., \& Fernández Salinas, V. (2017). El nuevo paradigma del patrimonio y su consideración con los paisajes: Conceptos, métodos y prospectivas. Documents d'Anàlisi Geogràfica, 63(1), 129-151. 63. http://dx.doi.org/10.5565/rev/dag.344

Tello Aragay, E. (1999). La formación histórica de los paisajes agrarios mediterráneos: una aproximación coevolutiva. Historia Agraria, 19, 195-212. Retrieved from http://www. historiaagraria.com/articulo. php?id=227\&num=19

Vidal i Moranta, T., \& Pol, E. (2005). La apropiación del espacio: una propuesta teórica para comprender la vinculación entre las personas y los lugares. Anuario de Psicología, 36(3), $281-$ 297. Retrieved from http://hdl.handle.net/2445/99095

Walker, A.J., \& Ryan, R.L. (2008). Place attachment and landscape preservation in rural New England: A Maine case study. Landscape and Urban Planning, 86, 141152. http://dx.doi.org/10.1016/j.landurbplan.2008.02.001

Wheeler, R. (2014). Mining memories in a rural community: Landscape, temporality and place identity. Journal of Rural Studies, 36, 22-32. http://dx.doi.org/10.1016/j.jrurstud.2014.06.005 